\title{
Modelling cloud processing of aerosol during the ACE-2 HILLCLOUD experiment
}

\author{
By MICHAEL J. FLYNN ${ }^{1 *}$, KEITH N. BOWER ${ }^{1}$, THOMAS W. CHOULARTON ${ }^{1}$, WOLFRAM \\ WOBROCK $^{2}$, JYRKI M. MÄKELÄ ${ }^{3}$, BENGT MARTINSSON ${ }^{4}$, GÖRAN FRANK ${ }^{4}$, HANS- \\ CHRISTEN HANSSON ${ }^{5}$, HANS KARLSSON ${ }^{5}$ and PAOLO LAJ ${ }^{6},{ }^{1}$ Atmospheric Physics Research \\ Group, Physics Department, University of Manchester Institute of Science and Technology, PO Box 88, \\ Manchester, M60 1QD, UK; ${ }^{2}$ Laboratoir de Meteorologie Physique, 24, Ave. des Landais, 63177 Aubiere \\ Cedex, France; ${ }^{3}$ Department of Physics, University of Helsinki, Helsinki, Finland; ${ }^{4}$ Division Nuclear \\ Physics, University Lund, Lund, Sweden; ${ }^{5}$ Institute of Applied Environmental Research, University of \\ Stockholm, Stockholm, Sweden; ${ }^{6}$ Institute of Physics and Chemistry of the Lower and Upper Atmosphere, \\ Consiglio Nazionale delle Ricerche, Bologna, Italy
}

(Manuscript received 2 February 1999; in final form 19 October 1999)

\begin{abstract}
A numerical model has been used to simulate the conditions observed during the ACE-2 Hillcloud experiment and to study the processes which may be taking place. The model incorporates gas phase chemistry of sulphur and nitrogen compounds upstream of the cloud, and the interaction of aerosol, precursor trace gases and oxidants within the cloud. Gas phase and aerosol inputs to the model have been provided from measurements made in the field. Dynamics of the air flow over the hill consisted of simple prescribed dynamics based on wind speed measurements, and also for some cases modelled dynamics. In this modelling study, it was found that during clean case studies particles down to $40-55 \mathrm{~nm}$ diameter were activated to form cloud droplets, the total number of droplets formed ranging from 200 to $400 \mathrm{drops} / \mathrm{cm}^{3}$. Significant modification of the aerosol spectra due to cloud processing was observed. In polluted cases particles down to $65-80 \mathrm{~nm}$ diameter were activated to form cloud droplets, the total number of droplets ranging from 800 to $2800 \mathrm{drops} / \mathrm{cm}^{3}$. Modification of the aerosol spectra due to cloud processing was slight. In all cases, changes in the aerosol spectra were due to both the uptake of $\mathrm{HNO}_{3}, \mathrm{HCl}, \mathrm{NH}_{3}$ and $\mathrm{SO}_{2}$ from the gas phase, (the $\mathrm{SO}_{2}$ being oxidised to sulphate) and the repartitioning of species such as $\mathrm{HNO}_{3}, \mathrm{HCl}$, and $\mathrm{NH}_{3}$ from larger particles onto smaller ones. Modelling results have been compared with observations made. Modelled droplet numbers are typically within $20 \%$ of the best measured values. The mode of the droplet distribution typically around $10-20 \mu \mathrm{m}$ for clean cases and $4-8 \mu \mathrm{m}$ for polluted cases was found to be in good agreement with the measured values of 10-25 $\mu \mathrm{m}$ for clean cases, but not in such good agreement for polluted cases. Measurements of upwind and interstitial aerosol distributions showed that the smallest particles activated were 30 and $50 \mathrm{~nm}$ for clean and polluted cases respectively, slightly smaller than the model values quoted above. Measured upwind and downwind aerosol spectra showed similar modification to that predicted by the model in eight out of the eleven model runs carried out. Chemistry measurements also give general evidence for both the uptake of species from the gas phase, and repartitioning of species from large particles onto smaller ones, though comparisons for individual cases are more difficult. From this modelling study, it can be concluded that in general, in the remote environment the exchange of hydrochloric acid, nitric acid and ammonia between aerosol particles and take up from the
\end{abstract}

* Corresponding author.

e-mail: mccpemf2@fs2.ee.umist.ac.uk

Tellus 52B (2000), 2 
gas phase in the vicinity of cloud may be a very important mechanism in regulating the evolution of the aerosol spectrum. Further, the much more linear relationship between cloud droplet and accumulation mode aerosol number, which was observed in the measurements made during the ACE-2 HILLCLOUD project is supported by these modelling results. The implications of this for the indirect effect will be explored in future work.

\section{Introduction}

The ACE-2 HILLCLOUD experiment used a hill cap cloud forming on the island of Tenerife as a natural flow through reactor to study the response of cloud microphysics to the aerosol properties and gases in the airstream entering the cloud and to study processing of aerosol and trace gases within the cloud. During the HILLCLOUD experiment, measurements of gas and aerosol properties were made at five major sites. Two of these sites, Hidalgo and Taganana were upwind of the cloud. Hidalgo is a coastal site located some distance away from the other measurement sites, the Taganana site is located in the village of Taganana, and is immediately upwind of the summit measurement site. The other sites were located at El Bailadero (summit), Paiba (Downwind), and Izania (free troposphere). A full description of the HILLCLOUD experiment, including details of site locations, measurements made, and major results obtained can be found in the HILLCLOUD overview paper (Bower et al., 2000). This paper specifically describes results of modelling work carried out using ACE-2 HILLCLOUD field measurements as input.

Cloud processing is a very important mechanism in controlling the growth of aerosol particles to a size where they may be optically active. Uptake of matter from the gas phase is somewhat dependant on the surface area of the particles, so for dry aerosol most of the mass is deposited onto the largest particles. However once particles become activated to form cloud droplets, the spread in particle diameter is much smaller, thus matter scavenged from the gas phase is distributed more evenly over all particles. In addition aqueous phase chemistry may take place in droplets adding mass to the particle upon which the drop formed. This cloud processing may cause the smallest particles activated to grow significantly in a much shorter period of time than would otherwise be possible.
Previous modelling studies include those done as part of the Great Dun Fell series of experiments, where this model was used to predict cloud droplet number and the aerosol modification caused by a single passage through a hill cap cloud (Bower et al., 1999; Bradbury et al., 1999). It was found in these studies that the uptake of $\mathrm{SO}_{2}$ and its aqueous phase oxidation to sulphate was the dominant factor in determining the evolution of the aerosol spectrum within the cloud.

In this study, the model is being used to examine processes taking place in a remote marine environment, rather than an environment heavily influenced by nearby anthropogenic activities as was the case at Great Dun Fell. Air masses arriving at Tenerife, even those originating from Europe during polluted events had travelled over the ocean for a number of days, leading to considerable ageing of particulate matter in the air mass, and reduction of gas phase concentrations of species associated with anthropogenic pollution. Further the area is likely to be more heavily influenced by natural processes such as production of $\mathrm{SO}_{2}$ from the oxidation of DMS, and mechanical production of aerosol particles from the sea surface.

The object of this modelling work was to determine which processes are important in governing evolution of the aerosol spectra under such conditions, and to attempt to reproduce microphysical properties of the cloud which were observed in the field (Martinsson et al., 2000).

\section{Introduction to the model}

The UMIST hill cloud model has been developed over a number of years to study chemical and physical processes occurring in a hill cap cloud. It is a Lagrangian type model which computes dynamics, microphysics, and chemistry for an orographic hill cap cloud. Descriptions of the 
model and applications it has been used for can be found in the literature (Sander et al., 1994; Bower et al., 1997; Bradbury et al., 1999).

Essentially, the model follows a parcel of moist air as it passes over a hill. As the parcel rises it is cooled adiabatically, and becomes supersaturated. Droplets form on larger aerosol particles according to the Köhler equation. Gas phase species are scavenged into droplets and undergo chemical reactions in the aqueous phase. As the air descends on the other side of the hill droplets evaporate, and any matter with a low vapour pressure scavenged or generated as a result of aqueous phase chemistry, adds mass to the aerosol particles upon which the droplets formed.

\subsection{Gas phase}

The gas phase module has undergone substantial development, and is now designed to run for an extended period of time before the arrival of the air parcel at the hill and formation of cloud. The purpose of this is to model production of $\mathrm{SO}_{2}$ from the oxidation of dimethyl sulphide (DMS). The gas phase module currently consists of two sub-modules which may be run separately, one containing reactions specific to the oxidation of DMS, the other containing reactions of species such as $\mathrm{NO}_{3}, \mathrm{OH}, \mathrm{O}_{3}$ and $\mathrm{H}_{2} \mathrm{O}_{2}$. Where trace gas measurements are available immediately upwind of cloud these are used in preference to values which would be produced by an extended run of the gas phase model. When measurements are used as input for the model, the module dealing with general gas phase chemistry is allowed to continue but the DMS module is disabled. This is because the typical time for the passage of air through the cloud on Tenerife was about five to ten minutes, far too short for any significant production of $\mathrm{SO}_{2}$ from DMS.

As input for this modelling study was based on measurements, only the detailed reaction schemes for nitrogen and sulphur chemistry, and the production and destruction of the important oxidants $\mathrm{O}_{3}, \mathrm{H}_{2} \mathrm{O}_{2}$, and $\mathrm{OH}$, which were permitted to run will be discussed here. In this reaction scheme thermal and photolytic reactions are included. The photolytic reaction rates are parameterized in terms of solar zenith angle according to:
Reaction rate $=\mathrm{PRL} \times \cos (\text { zenith })^{\mathrm{PRM}}$

$$
\times \exp \left(\frac{\text { PRN }}{\cos (\text { zenith })}\right) .
$$

Here zenith is the solar zenith angle, the angle between the position of the sun and the normal to the surface of the earth ignoring local roughness. The constants PRL, PRM and PRN are species specific and take account of the energy needed for the reaction and the effect of the atmosphere on these photons. At present no parameterisation has been developed to deal with the effects of cloud cover on photolytic reaction rates.

Fig. 1 illustrates nitrogen chemistry included in the model, and Table 1 gives a full list of gas phase reactions included, along with rate constants used.

\subsection{Dynamics}

The model follows a parcel of air moving along a trajectory, which is calculated from its current position and velocity in the horizontal and vertical directions. The model interpolates between data points in the trajectory information, and calculates current height from the vertical velocities. Dynamics data are obtained from a look-up file, in which the data provided may be the output from flow modelling, or simple prescribed dynamics consisting of fixed horizontal and vertical velocities based on measurements made in the field. The dynamics module also allows the option of considering entrainment of free-tropospheric air at cloud top.

\subsection{Microphysics}

The microphysics module is a one-dimensional adiabatic growth model. An initial aerosol spectrum is supplied containing details of particle size, number, solubility, and the chemical composition of soluble material for a number of discrete size categories. The initial droplet spectrum at cloud base is obtained from this initial aerosol spectrum and a solution of eq. (2), the Köhler equation (Wallace and Hobbs, 1997; Pruppacher and Klett, 1997) at $99 \%$ humidity for each category of input aerosol.

$\frac{e^{\prime}}{e_{\mathrm{s}}}=\left(\exp \frac{2 \sigma^{\prime}}{n^{\prime} k T r}\right)\left[1+\frac{i m M_{\mathrm{w}}}{M_{\mathrm{s}}\left(\frac{4}{3} \pi r^{3} \rho^{\prime}-m\right)}\right]^{-1}$. 


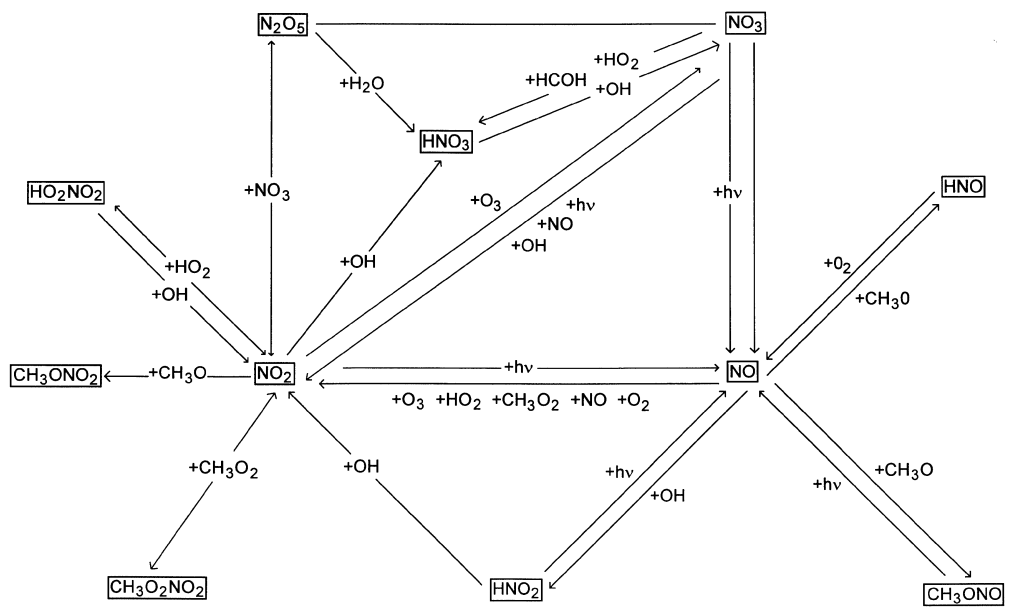

Fig. 1. The gas phase nitrogen cycle as included in the model. This reaction schematic is based on the reactions involving nitrogen listed in Table 1.

Table 1. All gas phase reactions included in the model except those involved in the oxidation of DMS, since DMS oxidation was switched off for the present study

(A) Photolytic reactions

\begin{tabular}{lcccr}
\hline Reaction & PRL & PRM & PRN & Ref. \\
\hline $\mathrm{NO}_{2}+h v \rightarrow \mathrm{NO}+\mathrm{O}\left({ }^{3} \mathrm{P}\right)$ & $1.11 \times 10^{-2}$ & 0.397 & 0.183 & 3 \\
$\mathrm{O}_{3}+h v \rightarrow \mathrm{O}\left({ }^{3} \mathrm{P}\right)+\mathrm{O}_{2}$ & $5.22 \times 10^{-4}$ & 0.322 & 0.079 & 3 \\
$\mathrm{O}_{3}+h v \rightarrow \mathrm{O}\left({ }^{1} \mathrm{D}\right)+\mathrm{O}_{2}$ & $8.98 \times 10^{-5}$ & 1.486 & 0.936 & 3 \\
$\mathrm{H}_{2} \mathrm{O}_{2}+h v \rightarrow 2 \mathrm{OH}$ & $1.06 \times 10^{-5}$ & 0.8 & 0.243 & 3 \\
$\mathrm{HNO}_{2}+h v \rightarrow \mathrm{NO}+\mathrm{OH}$ & $2.48 \times 10^{-3}$ & 0.431 & 0.194 & 3 \\
$\mathrm{NO}_{3}+h v \rightarrow 0.3 \mathrm{NO}+0.7 \mathrm{NO}_{2}+0.7 \mathrm{O}\left({ }^{3} \mathrm{P}\right)$ & $15.5 \times \mathrm{JNO}_{2}$ & & & 1 \\
$\mathrm{HNO}_{3}+h v \rightarrow \mathrm{NO}_{2}+\mathrm{OH}$ & $1.04 \times 10^{-6}$ & 1.371 & 0.466 & 1 \\
$\mathrm{HCHO}+h v \rightarrow 2 \mathrm{HO}_{2}+\mathrm{CO}$ & $4.87 \times 10^{-5}$ & 0.781 & 0.349 & 3 \\
$\mathrm{HCHO}+h v \rightarrow \mathrm{H}_{2} \mathrm{CO}$ & $3.3 \times 10^{-3} \times \mathrm{JNO}_{2}$ & & & 1 \\
$\mathrm{CH}_{3} \mathrm{ONO}+h v \rightarrow \mathrm{CH}_{3} \mathrm{O}+\mathrm{NO}$ & $0.17 \times \mathrm{JNO}_{2}$ & & & 1 \\
\hline
\end{tabular}

Here $e^{\prime}=$ vapour pressure of air adjacent to a droplet of given radius $r, \sigma^{\prime}$ and $n^{\prime}=$ surface energy and number density of water molecules in the solution respectively, $m=$ mass of salt dissolved in droplet, $i=$ no. of ions each salt molecule dissociates into, $M_{s}=$ molecular mass of salt, $M_{w}=$ molecular mass of water.

The spectrum evolves as the parcel passes over the hill and becomes supersaturated with some particles activating as determined by eq. (2) to form cloud droplets. As the air continues to rise, supersaturation increases, and activated droplets grow by vapour diffusion. The rate of this growth is determined by:

$\frac{\mathrm{d} r}{\mathrm{~d} t}=\frac{1}{r} \frac{D \rho_{\mathrm{v}}(\infty)}{\rho_{1}} S$,

where $D=$ diffusion coefficient of water vapour in air as a rate of mass flow across a unit area in the presence of unit vapour density gradient, $\rho_{\mathrm{v}}(\infty)=$ vapour density a large distance from the droplet, $\rho_{1}=$ density of the liquid.

Growth by coagulation of droplets, and formation of precipitation is not included in this model. The justification for this is that the time scale for these processes is typically longer than that for a 
Table 1 (cont'd)

(B) Thermal reactions

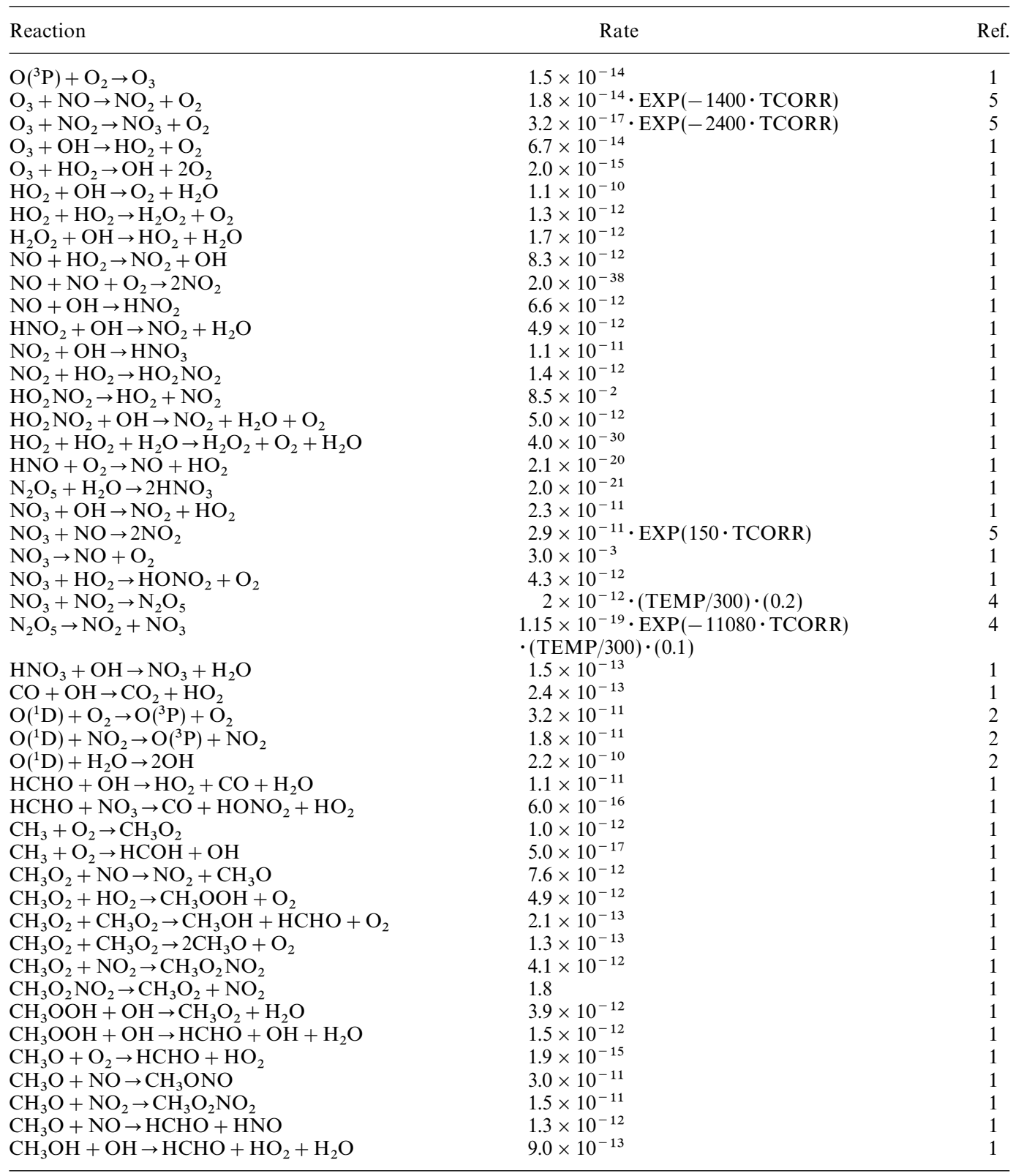

Refs. for Tables 1a, b.

1. Yin et al. (1990).

2. Atkinson et al. (1992).

3. Grenfell et al. (1999).

4. Atkinson et al. (1989).

5. DeMore et al. (1990).

TCORR $=(1 / T-1 / 298)$.

Tellus 52B (2000), 2 
single pass through a hill cap cloud. The model also calculates temperature, pressure and supersaturation as the air parcel passes over the hill (Sander et al., 1994). Once the air parcel has passed over the hill, droplets evaporate, and the model outputs a dry aerosol spectrum in which aerosol sizes are calculated from the new quantities of soluble material (and the original insoluble material) contained within them.

Table 2. Aqueous phase reactions included in the model

\begin{tabular}{|c|c|c|}
\hline Reaction & $\begin{array}{l}\text { Reaction } \\
\text { rate }\end{array}$ & Ref. \\
\hline $\mathrm{HSO}_{3}^{-}+\mathrm{H}_{2} \mathrm{O}_{2} \rightarrow \mathrm{SO}_{4}^{2-}+\mathrm{H}^{+}+\mathrm{H}_{2} \mathrm{O}$ & (a) & 1 \\
\hline $\mathrm{HSO}_{3}^{-}+\mathrm{O}_{3} \rightarrow \mathrm{SO}_{4}^{2-}+\mathrm{H}^{+}+\mathrm{O}_{2}$ & $4.2 \times 10^{5}$ & 2 \\
\hline $\mathrm{SO}_{3}^{2-}+\mathrm{O}_{3} \rightarrow \mathrm{SO}_{4}^{2-}+\mathrm{O}_{2}$ & $1.5 \times 10^{9}$ & 2 \\
\hline $\mathrm{NO}_{2}^{-}+\mathrm{O}_{3}^{-} \rightarrow \mathrm{NO}_{3}^{-}+\mathrm{O}_{2}^{-}$ & $5.0 \times 10^{5}$ & 3 \\
\hline $\mathrm{NO}_{3}+\mathrm{Cl}^{-} \rightarrow \mathrm{NO}_{3}^{-}+\mathrm{Cl}$ & $1.0 \times 10^{8}$ & 4 \\
\hline $\mathrm{HSO}_{3}^{-}+\mathrm{NO}_{2} \rightarrow \mathrm{SO}_{4}^{2-}+\mathrm{NO}_{2}^{-}$ & $3.0 \times 10^{5}$ & 5 \\
\hline $\mathrm{SO}_{3}^{2-}+\mathrm{NO}_{2} \rightarrow \mathrm{SO}_{4}^{2-}+\mathrm{NO}_{2}^{-2}$ & $1.0 \times 10^{7}$ & 5 \\
\hline $\mathrm{S}(\mathrm{IV})+\mathrm{N}(\mathrm{III}) \rightarrow \mathrm{SO}_{4}^{2-}+0.5 \mathrm{NO}_{2}$ & (b) & 1 \\
\hline $\mathrm{SO}_{2}+\mathrm{NO}_{3} \stackrel{\mathrm{H}_{2} \mathrm{O}}{\longrightarrow} \mathrm{SO}_{3}^{-}+\mathrm{NO}_{3}^{-}+2 \mathrm{H}^{+}$ & $2.3 \times 10^{8}$ & 6 \\
\hline $\mathrm{HSO}_{3}^{-}+\mathrm{NO}_{3} \rightarrow \mathrm{SO}_{3}+\mathrm{NO}_{3}^{-}+\mathrm{H}^{+}$ & $1.4 \times 10^{9}$ & 6 \\
\hline $\mathrm{HSO}_{3}^{-}+\mathrm{Fe}^{3+} \rightarrow \mathrm{SO}_{3}+\mathrm{H}^{+}+\mathrm{Fe}^{2+}$ & $3.2 \times 10^{2}$ & 7 \\
\hline $\mathrm{Cl}_{2}^{-}+\mathrm{HSO}_{3}^{-} \rightarrow 2 \mathrm{Cl}^{-}+\mathrm{SO}_{3}+\mathrm{H}^{+}$ & $3.4 \times 10^{8}$ & 8 \\
\hline $\mathrm{Cl}_{2}^{-}+\mathrm{SO}_{3}^{2-} \rightarrow 2 \mathrm{Cl}^{-}+\mathrm{SO}_{3}$ & $3.4 \times 10^{8}$ & 8 \\
\hline $\mathrm{SO}_{3}^{-}+\mathrm{O}_{2} \rightarrow \mathrm{SO}_{5}^{-}$ & $1.5 \times 10^{9}$ & 8 \\
\hline $\mathrm{SO}_{5}^{-}+\mathrm{HSO}_{3}^{-} \rightarrow \mathrm{HSO}_{5}^{-}+\mathrm{SO}_{3}^{-}$ & $2.5 \times 10^{4}$ & 8 \\
\hline $\mathrm{SO}_{5}^{-}+\mathrm{SO}_{3}^{2-} \stackrel{\mathrm{H}^{+}}{\longrightarrow} \mathrm{HSO}_{5}^{-}+\mathrm{SO}_{3}^{-}$ & $3.6 \times 10^{6}$ & 8,9 \\
\hline $\mathrm{SO}_{5}^{-}+\mathrm{HSO}_{3}^{-} \rightarrow \mathrm{SO}_{4}^{-}+\mathrm{SO}_{4}^{2-}+\mathrm{H}^{+}$ & $7.5 \times 10^{4}$ & 8 \\
\hline $\mathrm{SO}_{5}^{-}+\mathrm{SO}_{3}^{2-} \rightarrow \mathrm{SO}_{4}^{-}+\mathrm{SO}_{4}^{2-}$ & $9.4 \times 10^{6}$ & 8,9 \\
\hline $\mathrm{SO}_{5}^{-}+\mathrm{SO}_{5}^{-} \rightarrow 2 \mathrm{SO}_{4}^{-}+\mathrm{O}_{2}^{-}$ & 0 & 17 \\
\hline $\mathrm{SO}_{4}^{-}+\mathrm{HSO}_{3}^{-} \rightarrow \mathrm{SO}_{3}^{-}+\mathrm{SO}_{4}^{2-}+\mathrm{H}^{+}$ & $8.0 \times 10^{8}$ & 8 \\
\hline $\mathrm{SO}_{4}^{-}+\mathrm{SO}_{3}^{2-} \rightarrow \mathrm{SO}_{3}^{-}+\mathrm{SO}_{4}^{2-}$ & $4.6 \times 10^{8}$ & 8 \\
\hline $\mathrm{SO}_{4}^{-}+\mathrm{NO}_{2}^{-} \rightarrow \mathrm{SO}_{4}^{2-}+\mathrm{NO}_{2}$ & $9.8 \times 10^{8}$ & 10 \\
\hline $\mathrm{SO}_{4}^{-}+\mathrm{Cl}^{-} \rightarrow \mathrm{SO}_{4}^{2-}+\mathrm{Cl}$ & $2.7 \times 10^{8}$ & 11 \\
\hline $\mathrm{SO}_{4}^{-}+\mathrm{Fe}^{2+} \rightarrow \mathrm{SO}_{4}^{2-}+\mathrm{Fe}^{3+}$ & $8.6 \times 10^{8}$ & 12 \\
\hline $\mathrm{SO}_{5}^{-}+\mathrm{SO}_{5}^{-} \rightarrow \mathrm{S}_{2} \mathrm{O}_{8}^{2-}+\mathrm{O}_{2}$ & $1.4 \times 10^{8}$ & 8 \\
\hline $\mathrm{SO}_{5}^{-}+\mathrm{Fe}^{2+} \rightarrow \mathrm{HSO}_{5}^{-}+\mathrm{Fe}^{3+}$ & $4.0 \times 10^{6}$ & 17 \\
\hline $\begin{array}{l}\mathrm{H}^{+}+\mathrm{HSO}_{5}^{-}+\mathrm{HSO}_{3}^{-} \rightarrow 2 \mathrm{SO}_{4}^{2-} \\
+3 \mathrm{H}^{+}\end{array}$ & $7.1 \times 10^{6}$ & 13 \\
\hline $\mathrm{NO}_{3}^{-}+\mathrm{SO}_{4}^{-} \rightarrow \mathrm{SO}_{4}^{2-}+\mathrm{NO}_{3}$ & $2.3 \times 10^{5}$ & 14 \\
\hline $\mathrm{HSO}_{5}^{-}+\mathrm{Fe}^{2+} \rightarrow \mathrm{Fe}^{3+}+\mathrm{SO}_{4}^{-}+\mathrm{OH}^{-}$ & $3.0 \times 10^{4}$ & 15 \\
\hline $\mathrm{Cl}_{2}^{-}+\mathrm{Fe}^{2+} \rightarrow 2 \mathrm{Cl}^{-}+\mathrm{Fe}^{3+}$ & $1.4 \times 10^{7}$ & 16 \\
\hline $\mathrm{SO}_{3}^{-}+\mathrm{SO}_{3}^{-} \stackrel{\mathrm{H}_{2} \mathrm{O}}{\longrightarrow} \mathrm{SO}_{4}^{2-}+\mathrm{SO}_{3}^{2-}+2 \mathrm{H}^{+}$ & 0 & 17 \\
\hline
\end{tabular}

(a) $k=5.2 \times 10^{6} \times \frac{\left[H^{+}\right]}{\left[H^{+}\right]+0.1 \mathrm{~mol} / 1} \frac{1}{\mathrm{mols}}$.

(b) $\frac{\mathrm{d} c}{\mathrm{~d} t}=1.42 \times 10^{2} \frac{I^{3 / 2}}{\mathrm{~mol}^{3 / 2} \mathrm{~s}} \sqrt{\left[H^{+}\right][S(\mathrm{IV})][N(\mathrm{III})]}$.
Refs. for Table 2.

1. Martin \& Damschen (1981).

2. Maahs (1983).

3. Damschen \& Martin (1983).

4. Pandis \& Seinfeld (1989).

5. Warneck (1988).

6. Exner et al. (1992).

7. Reddy \& van Eldik (1992).

8. Huie \& Neta (1987).

9. Deister \& Warneck (1990).

10. Wine et al. (1989).

11. McElroy (1990).

12. Lee \& Rochelle (1987).

13. Betterton \& Hoffmann (1988).

14. Buxton et al. (1993).

15. Brandt \& van Eldik (1993).

16. Jayson et al. (1973).

17. Sander et al. (1995).

\subsection{Aqueous phase}

Aqueous chemistry is switched on once the liquid water content of the cloud exceeds $0.01 \mathrm{~g} / \mathrm{m}^{3}$, and only within drops larger than $1 \mu \mathrm{m}$. Gas phase species try to attain equilibrium with species in solution (the position of equilibrium being determined by Henry's law). The rate of scavenging or outgassing is limited by diffusion and transport across the gas-liquid interface according to the equation developed by Schwartz 1986:

$\frac{\mathrm{d} c_{\mathrm{a}}}{\mathrm{d} t}=k_{\mathrm{t}}\left(c_{\mathrm{g}}-c_{\mathrm{g}, \mathrm{eq}}\right)$,

where $k_{\mathrm{t}}=$ transfer coefficient, $c_{\mathrm{a}}=$ aqueous phase concentration, $c_{\mathrm{g}}=$ gas phase concentration, $c_{\mathrm{g}, \mathrm{eq}}=$ equilibrium gas phase concentration. The equilibrium concentration is calculated using the Henry law constant $K_{\mathrm{H}}$, according to:

$c_{\mathrm{g}, \mathrm{eq}}=\frac{c_{\mathrm{a}}}{\left(K_{\mathrm{H}} R T\right)}$.

The transfer coefficient takes into account diffusion, and transport across the gas-liquid interface and is defined by:

$k_{\mathrm{t}}=\left(\frac{r^{2}}{3 D_{\mathrm{g}}}+\frac{4 r}{3 \bar{v} \alpha}\right)^{-1}$,

where $D_{\mathrm{g}}=$ gas phase diffusivity, $\bar{v}=$ mean molecular speed, $r=$ droplet radius, $\alpha=$ accommodation coefficient (species specific). 
A full set of the chemical reactions included in the aqueous phase model along with the rate constants used is given in Table 2 . This chemistry includes a comprehensive reaction scheme for the oxidation of sulphur dioxide to sulphate.

\section{Modelling the ACE-2 hill cap cloud}

A number of time periods from the ACE-2 field campaign were selected as suitable times for modelling studies, these are given in Table 3. These periods were selected to represent a variety of clean and polluted conditions. They were also times when a good set of field data was available from all HILLCLOUD sites. This allowed as much input data for the model as was possible to be derived directly from field measurements, and the testing of model results against observations.

\subsection{Gas phase}

In the model (as discussed above) an option exists to run a complex gas phase reaction scheme for a considerable length of time before the air parcel reaches the hill. For this study, this was not required. Input gas phase concentrations to the model were obtained from measurements at the two upwind sites, located at Hidalgo and Taganana. Data were available for the following species, $\mathrm{O}_{3}, \mathrm{NO}, \mathrm{NO}_{2}, \mathrm{NO}_{3}, \mathrm{SO}_{2}, \mathrm{HNO}_{2}, \mathrm{HNO}_{3}$, $\mathrm{H}_{2} \mathrm{O}_{2}, \mathrm{NH}_{3}, \mathrm{HCl}$, and $\mathrm{HCOH}$. Where multiple data sets were available either from similar measurements made at both Taganana and Hidalgo, or from a number of different instruments measuring the same species at one site or another, these values have been compared. Generally the measurements at both sites and with different instruments compared very well, however in some cases there were significant differences. Where a choice was available values from Taganana have been assumed to be most representative of what was going into the cloud, and online measurements have been used in preference to filter pack measurements which integrate data over a three hour interval. Typical gas phase concentrations observed during the HILLCLOUD experiment are given in the overview paper (Bower et al., 2000).

\subsection{Dynamics}

A number of different sets of dynamics have been used for the model. Unfortunately measurements of updraft in the vicinity of cloud base, the height of which was known from ceiliometer measurements at Taganana were not made. Updraft at the summit site was measured, though this was considerably greater than the updraft at cloud base (the shape of the hill is such that the air accelerates over a short distance just before the summit). The simplest dynamics for this study were prescribed based on the measurements at the summit. In this scheme the air parcel travels at a fixed angle to the top of the hill, and down the other side at the same angle. The vertical velocity used is $17.5 \%$ of that measured at the summit, and the horizontal velocity is fixed to maintain a

Table 3. Model run times

\begin{tabular}{|c|c|c|c|c|}
\hline Model run no. & Date & Time & $\begin{array}{l}\text { HILLCLOUD } \\
\text { run no. }\end{array}$ & Conditions \\
\hline $1 \mathrm{~A}$ & 2 July 1997 & 03:30 & 1 & clean \\
\hline $2 \mathrm{~A}(\mathrm{M})$ & 8 July 1997 & 00:00 & 2 & polluted \\
\hline 2B (M) & 8 July 1997 & 06:00 & 2 & polluted \\
\hline $3 \mathrm{~A}(\mathrm{M})$ & 9 July 1997 & 00:00 & 3 & polluted \\
\hline $3 \mathrm{~B}$ & 9 July 1997 & 05:00 & 3 & polluted \\
\hline $4 \mathrm{~A}$ & 13 July 1997 & $04: 30$ & 4 & clean \\
\hline $5 \mathrm{~A}(\mathrm{R})$ & 14 July 1997 & 06:00 & 5 & clean \\
\hline $6 \mathrm{~A}$ & 17 July 1997 & 06:00 & 6 & intermediate \\
\hline $7 \mathrm{~A}$ & 20 July 1997 & $04: 45$ & 7 & intermediate \\
\hline $8 \mathrm{~A}$ & 22 July 1997 & $19: 00$ & 8 & clean \\
\hline $8 B$ & 22 July 1997 & $22: 00$ & 8 & clean \\
\hline
\end{tabular}

M: modelled dynamics were used for these runs; R: possible presence of the rotor structure above the downwind site.

Tellus 52B (2000), 2 
constant angle. The value of $17.5 \%$ was obtained empirically by finding the updraft required to match measured and modelled droplet concentrations at the summit site for a few of the runs. An average value was used, and then applied to all the other runs, it was found that this updraft gave good agreement between the model and measurements for all runs.

Observations indicated that during some measurement periods a rotor structure existed above the downwind site, increasing the transit time between the summit and downwind site by up to five minutes, hence causing the air parcel to spend a longer time in the cloud. A schematic representation of the rotor is shown in Fig. 2a. Furthermore, the presence of a rotor structure raised the possibility that a parcel of air may pass through the cloud more than once between the upwind and downwind sites. To look at the implications of this for cloud processing of aerosol, the simple dynamics were modified to increase the length of time spent in cloud and to cycle the air parcel through cloud a second time. Increasing the length of time in cloud was done in 2 ways, first by assuming the air parcel remained at the same height as the summit for an additional $5 \mathrm{~min}$, second by assuming that the parcel continued to rise for a further $2 \mathrm{~min}$, with a decreasing updraft, then gradually descended, such that in total a further $5 \mathrm{~min}$ is spent above the height of the summit site. Figure $2 \mathrm{~b}$ shows how the rotor structure has been dealt with in the model. Model run $5 \mathrm{~A}$, for which the measurements suggested a rotor may have been present was repeated with each of these sets of dynamics; all other inputs to the model were kept the same.

For 3 model runs (2A, 2B, and $3 \mathrm{~A})$, trajectories over the hill based on flow modelling using the Clark code were available (Clark et al., 1994; Wobrock et al., 1997). This flow modelling used a digitised topography representing the northern ridge of Tenerife, with soundings taken at Hidalgo providing data to initialise the model. For runs where modelled trajectories were available these were used as input to the hill cloud model in addition to the prescribed dynamics, and the results were compared. A comparison of the prescribed and modelled trajectories used is shown in Fig. 2c. Table 4 lists updrafts at cloud base used for each model run.
Entrainment is not considered during any model runs, as thermodynamic analysis carried out on the measurements of temperature and relative humidity at each of the sites showed very little evidence that entrainment was taking place (Bower et al., 1999).

\subsection{Aerosol - size distribution}

Size distributions used for model input were derived from a combination of differential mobility particle sizer (DMPS) measurements (Mäkelä et al., 1997; Jokinen et al., 1997), and active scattering aerosol spectrometer probe model $\mathrm{X}$ (ASASP-X) measurements. The DMPS measurements cover a size range $3.2-400 \mathrm{~nm}$, and the ASASP-X a size range of $100-3000 \mathrm{~nm}$. Comparisons showed ASASP-X and DMPS spectra to be in good agreement over the region of overlap, though ASASP-X spectra do fall off more quickly at the larger sizes than the DMPS. The reasons for these differences are beyond the scope of this paper. A typical set of DMPS and ASASP-X spectra are shown in Fig. 3. For the model input, DMPS data have been used unchanged up to $400 \mathrm{~nm}$, with the exception of the last channel. Here the number of particles has been averaged with the number measured by the ASASP-X. From 400-3000 nm ASASP-X data has been used. Above $3000 \mathrm{~nm}$ one extra size category was added, taking the total size range of aerosol input to $3.2-4500 \mathrm{~nm}$. A comparison was made between the integrated mass from the DMPS or ASASP-X and the Berner impactor gravimetric mass measurements over an equivalent size range. The results of this comparison for the largest impactor stage were used to determine the number of particles in the 3000-4500 $\mathrm{nm}$ model input size category.

\subsection{Aerosol - chemical composition}

Size segregated chemical composition of aerosol soluble fraction was derived from ion chromatography (IC) analysis of the five stage Berner impactor foils. These impactors sampled aerosol at ambient relative humidity, which was quite high, generally $80-95 \%$ at Taganana during cloud runs. DMPS and ASASP-X measurements are made on "dry" aerosol (RH about 20\%). Between relative humidities of 20 and $95 \%$ the diameter of a soluble particle may grow by a factor of $1.5-2.3$. 

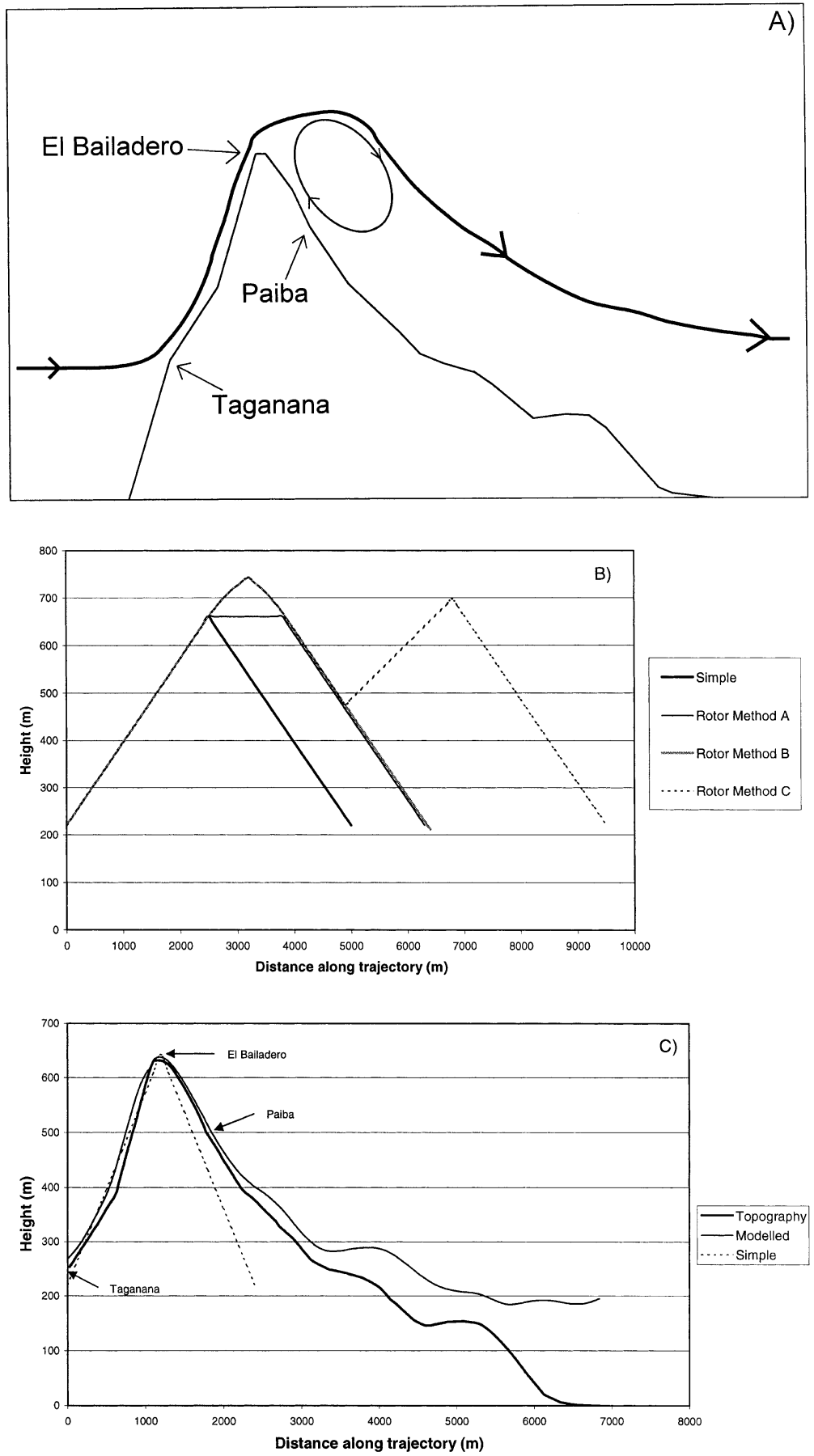

Fig. 2. Dynamics used in the modelling study. (A) Schematic illustration of the rotor dynamics which may have existed above the downwind site at Paiba during some measurement periods. (b) Schematic illustration of how the rotor dynamics have been modelled. In this diagram it is the vertical position which is important. The horizontal velocity was left unchanged throughout although in reality the horizontal velocity would reverse as the air went around the rotor. (C) A comparison of modelled and prescribed trajectories over the hill, showing the terrain and the measurement sites. 
Table 4. Updrafts at cloudbase for each model run

\begin{tabular}{cc}
\hline Model run no. & Updraft at cloudbase $(\mathrm{m} / \mathrm{s})$ \\
\hline 1A & 0.53 \\
2A & $1.78^{*}$ \\
2B & $1.82^{*}$ \\
3A & $1.44^{*}$ \\
3B & 1.45 \\
4A & 0.81 \\
5A & 0.75 \\
$6 \mathrm{~A}$ & 1.20 \\
$7 \mathrm{~A}$ & 1.56 \\
$8 \mathrm{~A}$ & 1.36 \\
8B & 1.39 \\
\hline
\end{tabular}

* Updrafts derived from flow modelling, other values are $17.5 \%$ of the measured updraft at the summit site.

Furthermore, impactor cut-off diameters are aerodynamic diameters, while DMPS and ASASP-X diameters are Stokes' diameters. Thus ambient impactor cut-off diameters cannot be used for matching chemistry to the DMPS size spectra. To match the impactor cuts to the DMPS spectra, the Stokes diameter was calculated from the aerodynamic diameter, and dry diameter equivalent cuts were calculated. To calculate Stokes diameter it is essential to know the density of the ambient particles. In this study it was assumed that dry particles have a density of $2.0 \mathrm{~g} / \mathrm{cm}^{3}$, the diameter growth factor was used to calculate the amount of water contained in ambient particles and hence their density. Dry diameter equivalent cuts for the impactors were calculated based on the measured chemical composition of particles in that size cut, and using hygroscopic tandem differential mobility analyser (HTDMA) measurements of growth factors (Swietlicki et al., 2000).

Data available from the impactor measurements included the following species: $\mathrm{Na}^{+}, \mathrm{Ca}^{2+}, \mathrm{Mg}^{2+}$, $\mathrm{NH}_{4}^{+}, \mathrm{Cl}^{-}, \mathrm{NO}_{3}^{-}$, and $\mathrm{SO}_{4}^{2-}$. The model input requires $\mathrm{Na}^{+}, \mathrm{NH}_{4}^{+}, \mathrm{Fe}^{3+}, \mathrm{Cl}^{-}, \mathrm{NO}_{3}^{-}, \mathrm{SO}_{4}^{2-}$, $\mathrm{OH}^{-}$, and $\mathrm{H}^{+}$. Calcium and magnesium were converted into sodium for the purpose of model input, so as to maintain the same amount of positively charged material. The total charge for all species was calculated, and hydrogen, or hydroxide added, to ensure electrically neutral aerosol. As no measurements of iron content in the aerosol were made, it was assumed that no iron was present in the aerosol. Gas phase measurements showed only small concentrations of $\mathrm{SO}_{2}$, but plenty of $\mathrm{H}_{2} \mathrm{O}_{2}$, its major oxidant in the aqueous phase. Hence the iron catalysed oxidation of $\mathrm{SO}_{2}$ was not considered to be important in this study.

Comparisons have been made between chemical and gravimetric mass, for both size segregated and bulk impactor data. These showed that in most cases the aerosol also consisted of some organic or insoluble material. In clean cases, only $50-70 \%$ of the gravimetric mass could be accounted for by the chemical mass from the IC analysis. In polluted cases this value rose to $100 \%$. A full chemical

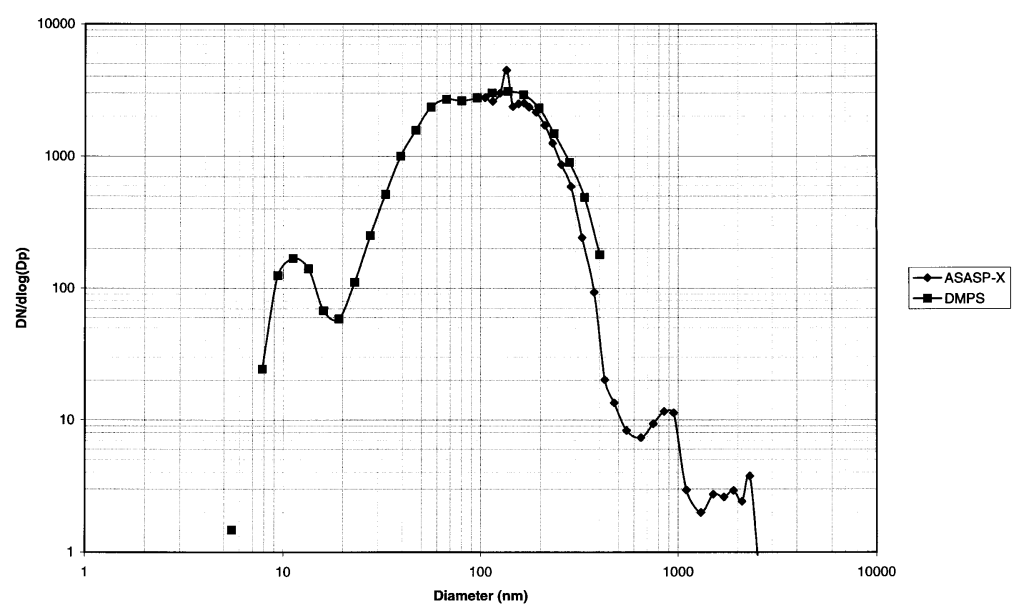

Fig. 3. Comparison of aerosol spectra measured at Taganana using the DMPS and the ASASP-X, a combination of these spectra was used as input for the model. This case is for a polluted run, 9 July 1997, 00:00 UTC. 
mass closure was carried out by Putaud et al. (2000). The hygroscopic tandem differential mobility analyser (HTDMA) data (Swietlicki et al., 2000) did not show such a significant reduction in solubility in the main hygroscopic mode during clean events, but reported additional less soluble hygroscopic modes more frequently. This suggested that some of the "missing" mass may be composed of soluble organic material and some externally mixed insoluble material.

For this modelling study solubility data were derived from HTDMA data as described in the next section. The chemical composition of the soluble fraction used for the model input was derived from IC analysis of Berner impactor foils, as described above.

\subsection{Aerosol - hygroscopic properties}

In the field, the HTDMA was used to measure hygroscopic growth factors of particles with seven different dry diameters in the size range of 35-440 nm (Swietlicki et al., 2000). These growth factors were used to calculate the soluble fraction of the particles. It has been shown experimentally that the soluble, and less soluble components of internally mixed aerosol take up water independently of one another (Virkkula et al., 1999). Hence the fraction of soluble material may be calculated provided the diameter growth factor for the particle is known, along with growth factors for each component. In principal these growth factors may be calculated from the chemical analysis of particles, and the size of the particle.

For the purpose of this modelling study a simplified method was used to calculate aerosol soluble fraction. It has been assumed that the particle consists of either pure ammonium sulphate, or pure sodium chloride, for which growth factors of 1.78 and 2.3 respectively for an increase of relative humidity from 20 to $90 \%$ were used. These soluble salts were assumed to be mixed with some completely insoluble material. The salt chosen depended on the dominant species in the chemical analysis of the aerosol. A further simplification was made in that any difference between the relative humidities for which growth factors for pure salts are quoted, and those at which the actual growth factors of the particles were measured, was ignored. Thus the soluble fraction is given by:

$\mathrm{Sf}=\frac{\mathrm{gf}_{(\mathrm{m})}^{3}-1}{\mathrm{gf}_{(\mathrm{a})}^{3}-1}$,

where $\mathrm{gf}_{(\mathrm{m})}$ is the measured growth factor, and $\mathrm{gf}_{(\mathrm{a})}$ is the assumed growth factor for the soluble material.

The soluble fraction for particles larger than the maximum size for which growth factors were measured was assumed to be equal to 1 , the validity of this assumption being confirmed by the fact that the largest sizes for which growth factors were measured had soluble fractions very close to 1. For particles smaller than those for which growth factors were measured, the soluble fraction was assumed to be equal to the soluble fraction of the smallest sizes for which growth factors were measured.

\section{Results}

From the model runs undertaken, listed in Table 3, model runs 3B and 8B have been selected as typical cases to represent polluted and clean conditions respectively. Detailed results and comparisons with measured data are given for these runs, while other cases are discussed in the text and summarised in tables.

\subsection{Cloud microphysical properties}

Cloud droplet numbers predicted by the model for each run are shown in Table 5, and are compared to droplet numbers measured by the droplet aerosol analyser (DAA), and forward scattering spectrometer probe (FSSP), and inferred by upwind and interstitial aerosol measurements. Generally there was very good agreement between modelled droplet number and both DAA measurements (values within $20 \%$ on average) and the implied droplet number from aerosol measurements (values within $10 \%$ on average). Some differences may be due to the longer integration time of 20-30 min with the DAA, and also the difficulty in determining the updraft at cloudbase. Comparison with the FSSP measurements was not as good, especially when very high droplet numbers are predicted (values within $25 \%$ for clean cases, and $40 \%$ for polluted cases on average). This was likely to be due to coincidence 
Table 5. Comparison of modeled and measured cloud droplet numbers

\begin{tabular}{ccccccc}
\hline & & & \multicolumn{3}{c}{ DAA droplet number ${ }^{2,3}$} & \\
\cline { 4 - 6 } $\begin{array}{c}\text { Model } \\
\text { run }\end{array}$ & $\begin{array}{c}\text { Model } \\
\text { droplet no. }\end{array}$ & $\begin{array}{c}{ }^{2} \\
\text { droplet no. }\end{array}$ & nearest & $\min$ & $\max$ & $\begin{array}{c}\text { Droplet no. } \\
\text { implied }^{4}\end{array}$ \\
\hline 1A & 183 & 149 & 49 & 36 & 295 & 165.76 \\
2A & 1854 & 1137 & 1587 & 1129 & 2962 & 1767.4 \\
2B & 2862 & 1465 & 2139 & 1129 & 2962 & 2894.5 \\
3A & 1530 & 955 & 1239 & 489 & 1722 & 1369.0 \\
3B & 1283 & 1015 & 1286 & 489 & 1722 & 1268.1 \\
4A & 316 & 301 & 331 & 299 & 386 & 438.3 \\
5A & 337 & 296 & 196 & 141 & 600 & 321.38 \\
6A & 848 & 597 & 724 & 374 & 724 & 931.1 \\
7A & 377 & 243 & 262 & 262 & 388 & 396.1 \\
8A & 275 & 81 & & & & 220.93 \\
8B & 205 & 133 & & & & 174.24 \\
\hline
\end{tabular}

${ }^{1}$ Where the modelled dynamics were available, they have been used.

${ }^{2}$ Nearest indicates droplet number from the measurement time nearest to the model run time. Min and max indicate the minimum and maximum droplet numbers measured during that HILLCLOUD run.

${ }^{3}$ Blanks are where data is missing during HILLCLOUD run 8.

${ }^{4}$ Droplet number implied from the difference between upwind and interstitial DMPS total number of particles with diameter $>0.42 \mu \mathrm{m}$.

error problems with FSSP measurements under conditions of high droplet concentration, the details of which are beyond the scope of this paper. The issue of measurement of very high numbers of droplets is discussed further by Martinsson et al. (2000).

Fig. 4 shows the relationship between predicted droplet number and the input aerosol number used in the model. This figure shows that there is an almost linear relationship between accumulation mode aerosol and droplet number. These results support findings from the measurements of Martinsson et al, and should be compared with measurements reported in that paper. These measurements and modelling results are in contrast to previous studies where a linear relationship has

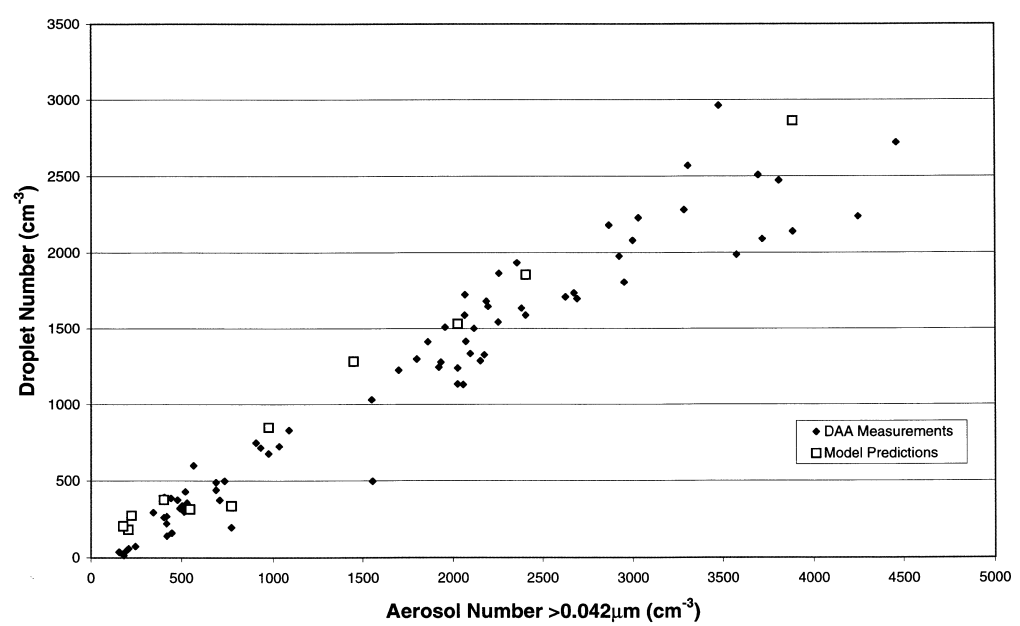

Fig. 4. Scatter plot of predicted droplet number against input aerosol number, for all the model runs, showing the linear relationship between the two. For comparison DAA measurements of cloud droplet number and upwind aerosol number are also shown. 
not been found, rather droplet numbers have levelled off at higher aerosol concentrations (within the same size range).

Cloud droplet spectra produced by the model are in good agreement with those measured by the FSSP for clean cases, but with larger differences for polluted cases. Examples of cloud droplet spectra for a clean and polluted case are shown in Fig. 5A, B, respectively. Table 6 compares the mode droplet diameter predicted by the model with measurements for each model run. Differences between modelled and FSSP spectra during polluted cases may be attributed to prob- lems with FSSP measurements under conditions of high droplet number which result in oversizing of measured droplets by an amount which is difficult to quantify, and hence to correct.

For clean studies as seen in Fig. 5A, the modelled droplet spectra were narrower than the measured spectra. The measurements showed higher numbers of both very small, and very large droplets than were predicted. A small number of additional larger droplets may be a result of droplets forming on large aerosol which were not included in the model input. Such aerosol were measured at Hidalgo, but were small in number (generally
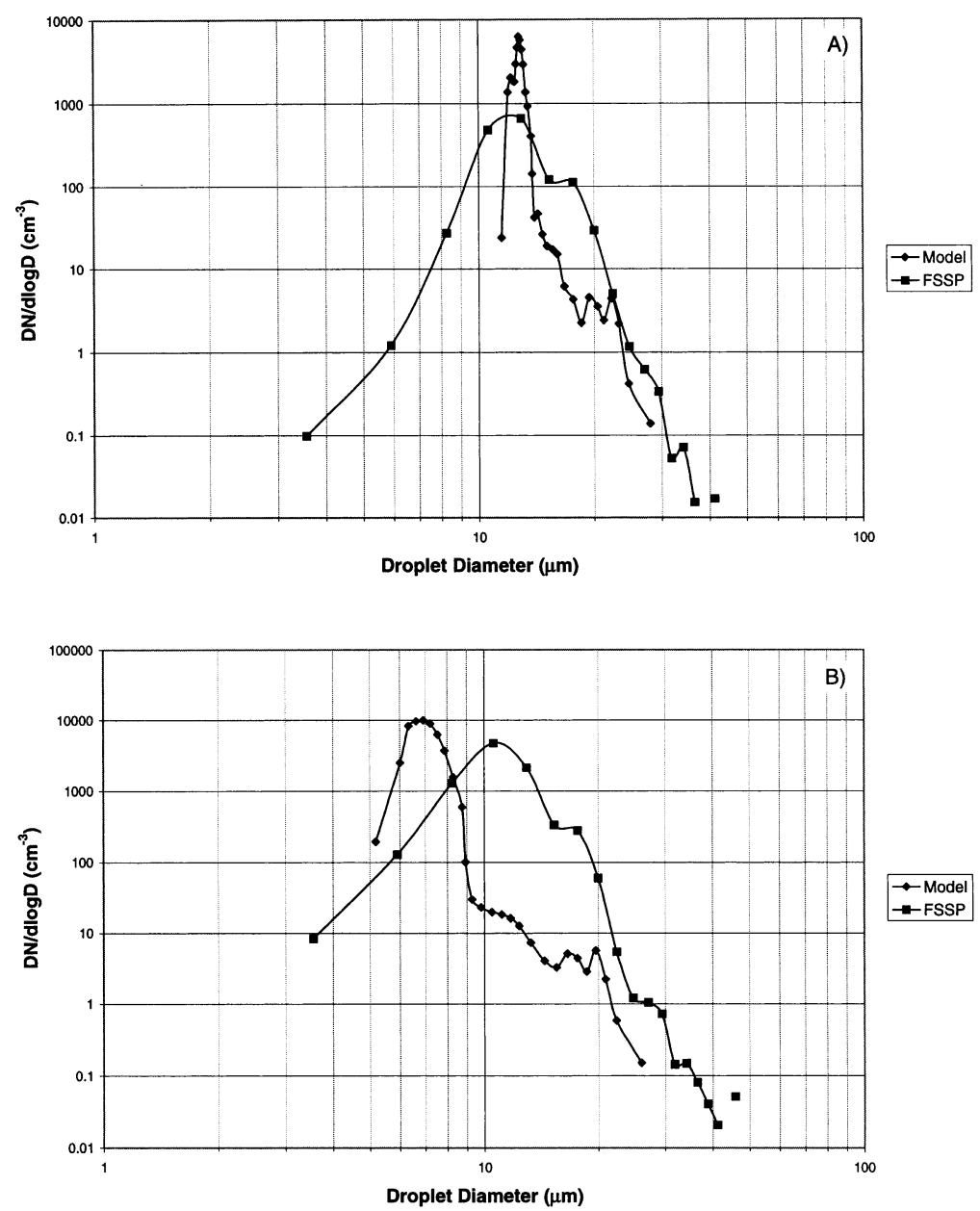

Fig. 5. Comparison of predicted droplet spectra, and those measured using the FSSP. (A) Typical clean case, Model run $8 \mathrm{~B}$. This shows good agreement between the model and FSSP measurements in regard to the mode diameter. (B) Typical polluted case, Model run 3B. This shows the poor agreement between the model and FSSP measurements during conditions of high droplet concentration.

Tellus 52B (2000), 2 
Table 6. Modelled and measured mode droplet diameter

\begin{tabular}{cccc}
\hline & \multicolumn{3}{c}{ Mode droplet diameter $(\mu \mathrm{m})$} \\
\cline { 2 - 4 } $\begin{array}{c}\text { Model } \\
\text { run no. }\end{array}$ & model & FSSP & DAA \\
\hline 1A & 18.5 & 22.35 & 11.9 \\
2A & 7.78 & 10.6 & 4.0 \\
2B & 6.0 & 10.6 & 4.5 \\
3A & 4.49 & 10.6 & 5.08 \\
3B & 6.92 & 10.6 & 4.5 \\
4A & 11.0 & 10.6 & 6.82 \\
5A & 12.8 & 10.6 & 6.82 \\
6A & 7.28 & 10.6 & 4.5 \\
7A & 11.1 & 10.6 & 6.82 \\
8A & 10.0 & 17.65 & \\
8B & 12.8 & 12.95 & \\
\hline
\end{tabular}

less than 10 particles $/ \mathrm{cm}^{3}$ ). Additional small droplets may result from a more complicated supersaturation history than was used in the model. Some model runs were carried out using dynamics that produced a more complicated supersaturation history in which there were two supersaturation peaks. It was found that having a second peak close to cloudbase did produce additional small droplets, but that a second supersaturation peak close to the summit, using the updraft measured at the summit site made no difference to the droplet spectra or the number of droplets activated. Thus, additional small droplets seen in the measurements may be the result of a more complicated supersaturation history close to cloudbase. It is also known that FSSP measurements tend to broaden the measured droplet spectra (Dye and Baumgardner, 1984).

\subsection{Changes in aerosol size spectra due to cloud processing}

Fig. 6 shows model input and output aerosol spectra for a clean and polluted case model runs $8 \mathrm{~B}$ and $3 \mathrm{~B}$ respectively. During clean cases there is significant modification of the smallest particles activated, which may be as small as $40 \mathrm{~nm}$ in diameter. During polluted cases very little modification takes place, possibly due to the fact that there is so much material in the aerosol phase that the small amount of mass added from the gas phase makes very little difference to the size distribution of the aerosol. In addition, in polluted cases the size of the smallest particles activated was larger at between $65-80 \mathrm{~nm}$ diameter. Table 7 gives a comparison between the size of the smallest particles activated in the model, with those determined from the observations (obtained by comparing upwind and interstitial DMPS measurements).

Some measured aerosol size distributions show support for model predictions of aerosol modification, with both the magnitude of the modification and the size range over which the modification occurs in agreement. This is the case for model runs $2 \mathrm{~A}-4 \mathrm{~A}, 6 \mathrm{~A}$ and $8 \mathrm{~A}-8 \mathrm{~B}$, however there is no evidence for aerosol modification seen in the measurements for model runs $1 \mathrm{~A}, 5 \mathrm{~A}$, and 7A. Runs where agreement was seen cover both clean and polluted conditions and showed significant modification during clean cases, with very little change during polluted cases. Fig. 7 shows a comparison between input and output measured aerosol spectra for a clean and polluted case (for the same periods investigated in model runs $8 \mathrm{~B}$ and $3 \mathrm{~B}$ ). This figure can be compared with Fig. 6, and shows the agreement between the model and measurements for these cases. Generally agree-

Table 7. Diameter of modelled and measured smallest particles activated

\begin{tabular}{clc}
\hline & \multicolumn{2}{c}{ Smallest particle activated (nm) } \\
\cline { 2 - 3 } $\begin{array}{c}\text { Model } \\
\text { run no. }\end{array}$ & model & measured \\
\hline 1A & 55.9 & 51.8 \\
2A & 71.8 & 71.97 \\
2B & 66.9 & 61.05 \\
3A & 80 & 84.83 \\
3B & 80 & 51.79 \\
4A & 55.9 & 51.79 \\
5A & 55.9 & 61.05 \\
6A & 66.9 & 51.79 \\
7A & 39.1 & 31.62 \\
8A & 39.1 & 37.27 \\
8B & 39.1 & 26.83 \\
\hline
\end{tabular}

Measured smallest particles activated are derived from a comparison of upwind and interstitial DMPS spectra. Diameter of smallest particles activated is the mid diameter of the first category where the interstitial DMPS spectra shows a significant reduction from the upwind DMPS spectra in the case of measurements, or the mid diameter of the first channel in which aerosol modification has occurred in the model. 

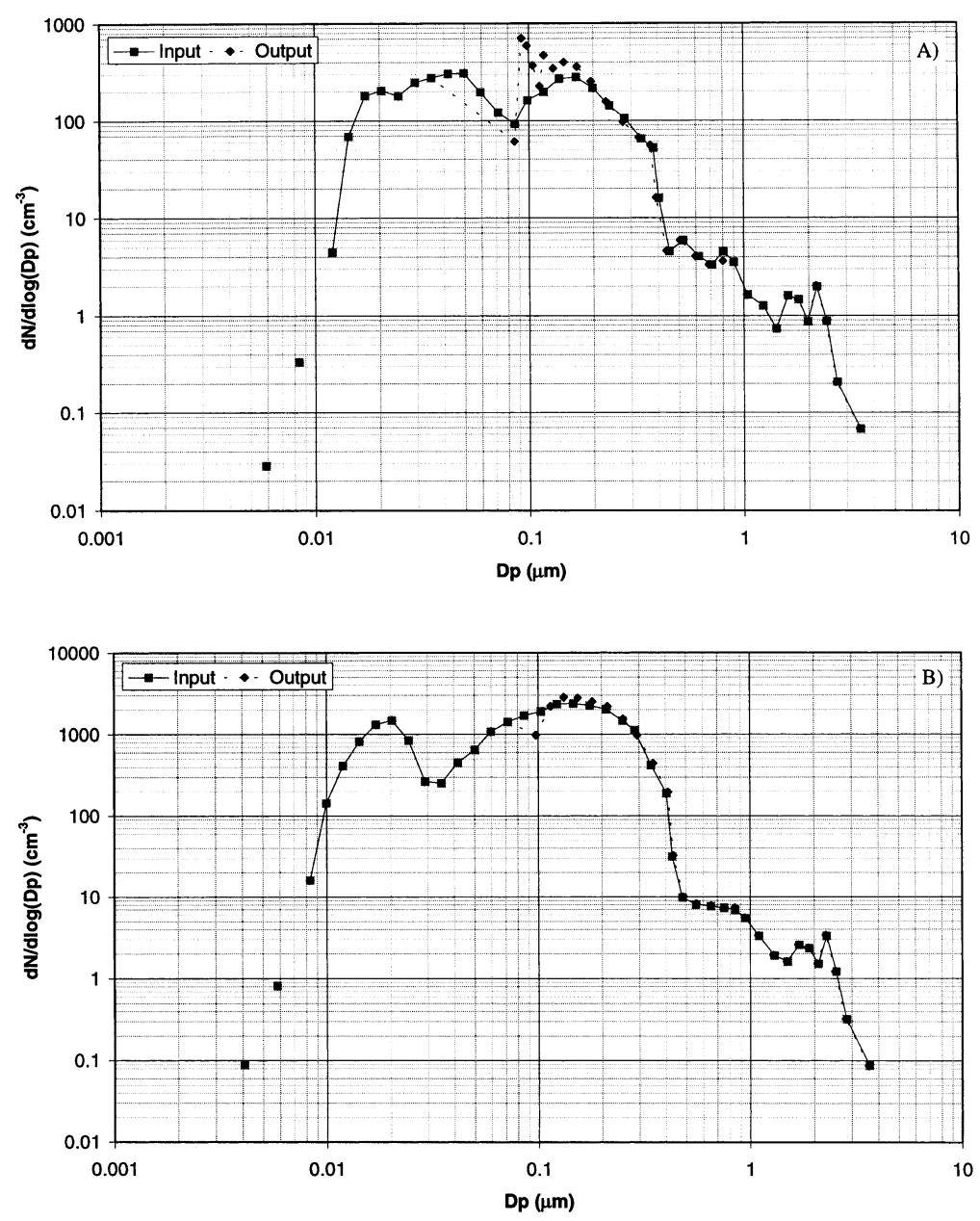

Fig. 6. (A) Modelled input and output aerosol spectra for the typical clean case, Model run 8B. (B) Modelled input and output aerosol spectra for the typical polluted case, Model run 3B. These figures may be compared with the measurements shown in Fig. 7.

ment was good, the main difference being that observations indicated that a few smaller particles were activated than were predicted by the model. This may be due to some particles at sizes larger than the smallest size activated remaining unactivated within the real cloud, whereas in the model all particles of a given size and solubility are either activated or not activated. To reproduce these observations would require a more complex hygroscopic aerosol input to the model (with aerosols of a given size - particularly at smaller sizes, having an external mix of hygroscopicities).

\subsection{Changes in aerosol chemistry due to cloud processing}

Typical input and output aerosol chemistry for clean conditions is shown in Fig. 8. In this plot from model run $8 \mathrm{~B}$, it can be seen that some aerosol growth was caused by the uptake of sulphur dioxide from the gas phase, and its oxidation to sulphate in the droplets. However nitrate, chloride and ammonium components increased (accounting for up to $97 \%$ of the mass increase of the smallest activated particles) due to the scaven- 

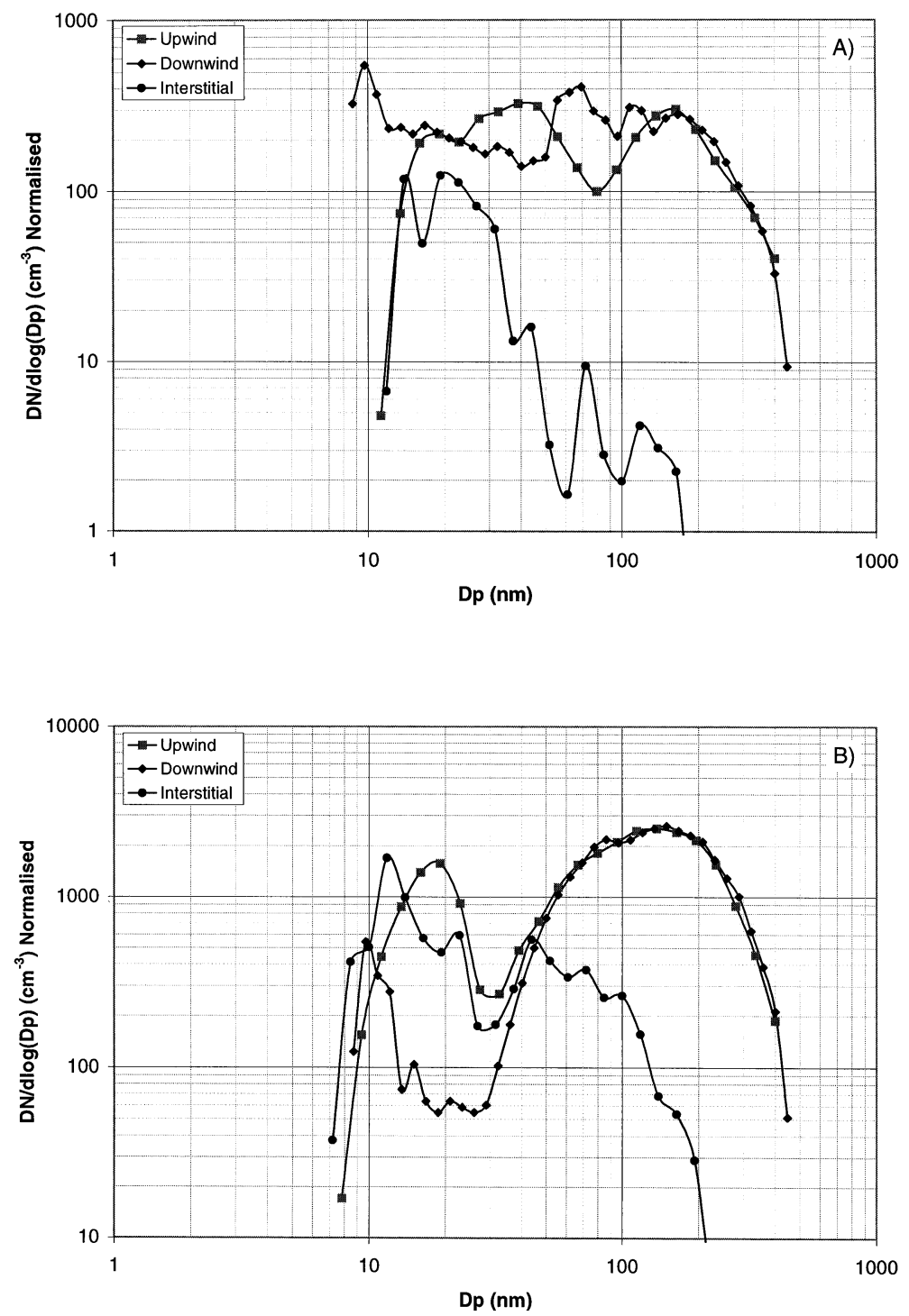

Fig. 7. (A) Observed upwind, interstitial and downwind DMPS spectra for the typical clean case, Model run 8 B. Observed upwind, interstitial and downwind DMPS spectra for the typical polluted case, Model run 3B. (B) The spectra from the downwind site has been normalised to correct for a suspected flow rate problem. The normalisation process has not affected the shape of the spectra. It can be seen from these figures, and from Fig. 6 that the modelled prediction of aerosol modification is in agreement with measurements.

ging of species from the gas phase onto the smallest particles activated, and also some repartitioning of these species from larger particles. In some cases, the repartitioning accounted for all of the growth of the smaller particles; however, in others, the scavenging from the gas phase was much more significant. In cases with high ammonium loading, ammonia is outgassed from the larger particles on activation contributing significantly to the concentration of the species in the gas phase even after 

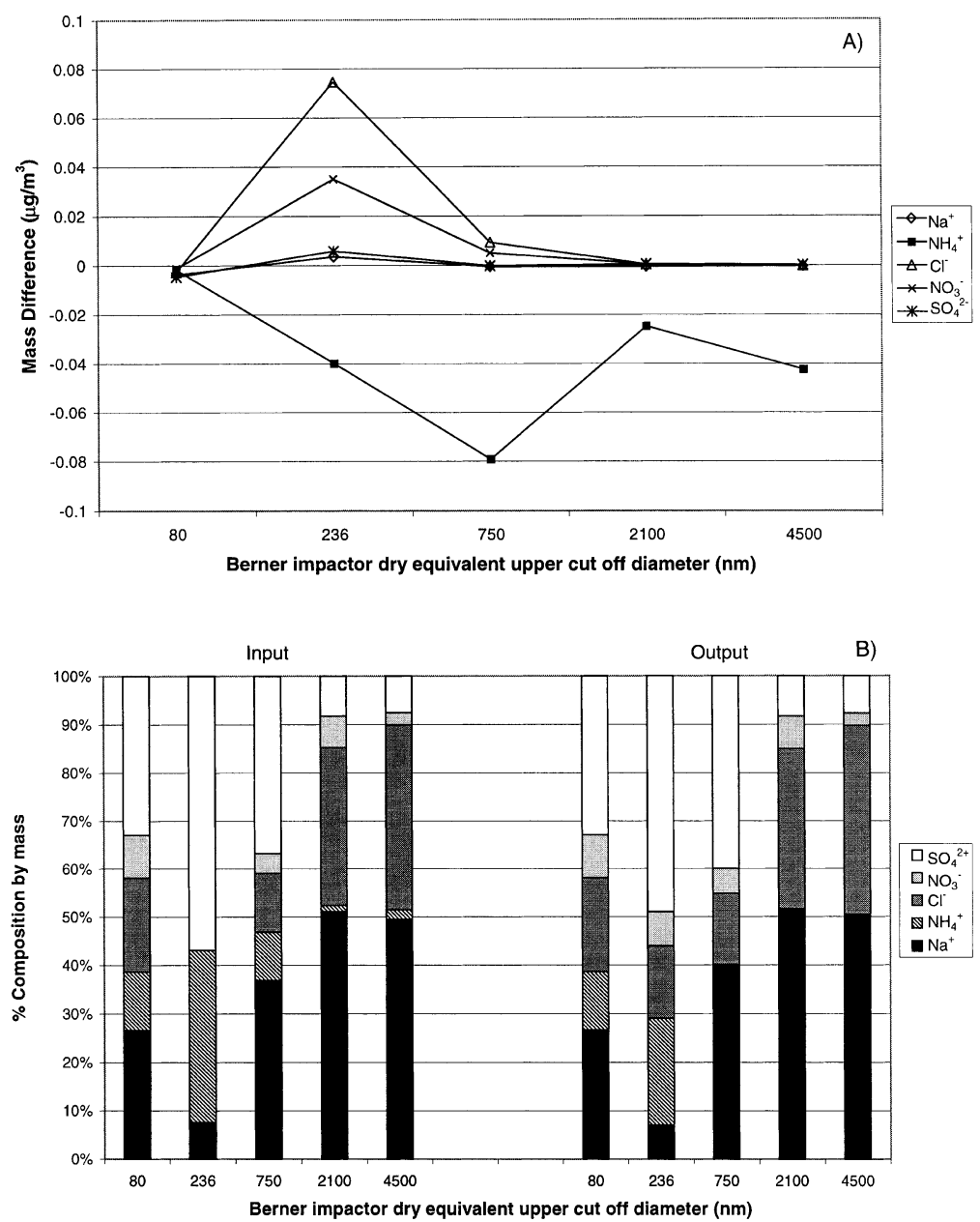

Fig. 8. Comparison of model input and output aerosol chemistry for the typical clean case, Model run 8B. (A) A plot of modelled mass increase between upwind and downwind sites for each species for each stage of the Berner impactor. (B) Input and output chemical composition by mass as a function of size. Each category corresponds to a Berner Impactor stage.

the cloud has evaporated. For example it can be seen (Fig. 8a) that for model run $8 \mathrm{~B}$ ammonia has outgassed from all aerosol larger than $0.13 \mu \mathrm{m}$. For this case an increase of gas phase ammonia from 0.06 to $0.33 \mathrm{ppbv}$ was predicted. Generally ammonia was also taken up onto the smaller particles. Outgassing occurs because high ammonium loadings in dry aerosol are locked in from the time the aerosol was in equilibrium with an ammonia rich gas phase. Aerosol phase ammonium in excess of gas phase ammonia cannot be liberated until aerosol become solutions which occurs at high relative humidity in the vicinity of cloud or in the cloud itself.

In polluted cases, the total mass added to the aerosol phase was larger than in the clean case (compare Figs. 8A and 9A). However, due to the very high number of particles over which the added mass was distributed absolute changes in soluble mass per particle were smaller typically by about a factor of 2 . This coupled with the larger size of the smallest activated particles in the polluted case gave a mass increase of only $10-60 \%$ for the smallest particles activated, compared with 
$1000 \%$ in clean cases. In these polluted cases there was very little take up of sulphur dioxide and most changes were due to the take up of nitrate and chloride from the gas phase, and the repartitioning of these species from larger particles onto smaller particles. In some polluted cases repartitioning accounted for up to $60 \%$ of the chloride gained by the small particles, and about $10 \%$ of the nitrate. Ammonia was taken up onto some particles and outgassed from others, depending on the $\mathrm{pH}$ of the particles. An example of the changes in aerosol chemistry is shown in Fig. 9 for the typical polluted case, model run $3 \mathrm{~B}$.

Repartitioning occurs because of the large differences in the composition of aerosol in different size ranges, reflecting the different sources of different sized aerosol. As cloud droplets grow, species are exchanged between gaseous and aqueous phases till all aerosol are in equilibrium with current gas phase concentrations. In many cases much of the initial gas phase concentration of each gas is scavenged by the growing cloud droplets. Thus leaving a deficit in the gas phase causing aerosol comprised of a large fraction of $\mathrm{NH}_{4}^{+}$, $\mathrm{Cl}^{-}, \mathrm{NO}_{3}^{-}$to be in excess over the gas phase, and hence to outgas. During evaporation increasing concentrations within the shrinking droplets probably then puts the concentrations in most aerosol in excess over gas phase concentrations leading to general outgassing. The aerosol will now be in equilibrium with the gas phase, and may have different compositions than those upon entering the cloud.

The uptake of $\mathrm{HNO}_{3}, \mathrm{HCl}$ and $\mathrm{NH}_{3}$, and the significance of these species in the modification of the aerosol spectrum is an important result of this modelling study. In previous studies the uptake of $\mathrm{SO}_{2}$ and its oxidation has been found to be the dominant process regulating the evolution of the aerosol spectrum. In this study although aqueous phase oxidation of $\mathrm{SO}_{2}$ is still of some importance, especially during clean cases, gain in the other species has a much more significant effect. This is true even in the case where the contribution of sulphate is greatest (typical clean case), and it is an order of magnitude less than the contribution due to $\mathrm{Cl}^{-} \mathrm{NO}_{3}^{-}$and $\mathrm{NH}_{4}^{+}$uptake. It is expected that the uptake of $\mathrm{HNO}_{3} \mathrm{HCl}$ and $\mathrm{NH}_{3}$ and sulphate produced will lead to permanent changes in the aerosol spectra, even though species outgas during droplet evaporation. The modification occurs because of the production of less volatile salts such as ammonium nitrate and ammonium chloride mixed with sulphate, and because of high ionic strength effects in solution moving the equilibrium between gas and aqueous phases. In some cases however, it is possible that some or all of the material taken up will be outgassed again as the droplets evaporate, particularly when stable salts are not formed or droplet evaporation is slow. This requires further investigation and will be carried out when routines for high ionic strength chemistry are added to the model.

Modelled chemistry results are generally in agreement with field data. Filter pack measurements of gases show some take up of $\mathrm{HNO}_{3}$ and $\mathrm{HCl}$ from the gas phase during all cloud events. Gas phase measurements of ammonia in some cases showed an increase between upwind and downwind sites, while in others a decrease was seen. This may be as a result of exchange of species in the cloud, or contamination of the measurements by local sources of ammonia. The uptake of $\mathrm{SO}_{2}$ and oxidation to sulphate is small, despite an excess of $\mathrm{H}_{2} \mathrm{O}_{2}$ in the gas and aqueous phases. This is also in agreement with gas phase measurements of $\mathrm{SO}_{2}$ which show very little change in $\mathrm{SO}_{2}$ concentration after passage through the cloud. This may be due to the short length of time spent by the air parcel within the hill cap cloud. The take up of $\mathrm{SO}_{2}$ by cloud droplets is limited by the rate at which it will diffuse into the drops, by low $\mathrm{pH}$ of some of the droplets, and the small concentration of $\mathrm{SO}_{2}$ available in the gas phase. Thus $\mathrm{SO}_{2}$ uptake into the drops was slow despite the fact that within the drops it was rapidly oxidised to sulphate by $\mathrm{H}_{2} \mathrm{O}_{2}$.

There is some support in the size resolved aerosol chemistry measurements for the uptake and repartitioning of nitrate and chloride onto the smaller particles especially for the clean case studies. Specific comparisons between modelled and measured size segregated aerosol chemistry were carried out, this was done by integrating up both the model output data and the downwind impactor measurements into two size fractions, the small fraction being $<240 \mathrm{~nm}$ dry diameter and the large fraction $>240 \mathrm{~nm}$ dry diameter. It was not possible to perform a more detailed comparison than this between modelled and measured aerosol chemistry because of the limitations in the size resolution of the impactor data. For model run 8B (model results shown in Fig. 8), it 

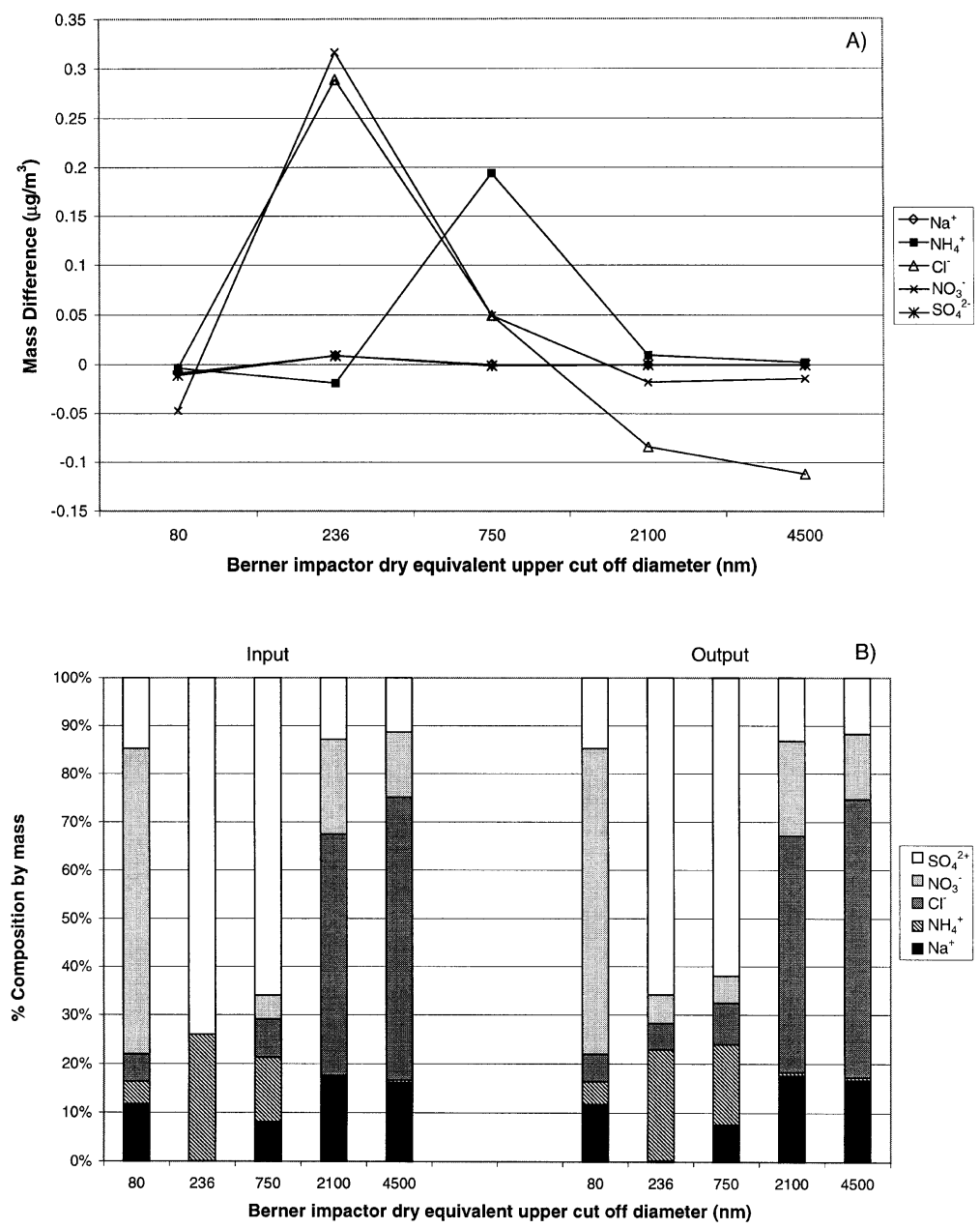

Fig. 9. Comparison of model input and output aerosol chemistry for the typical polluted case, Model run3B. (A) A plot of modelled mass increase between upwind and downwind sites for each species for each stage of the Berner impactor. (B) Input and output chemical composition by mass as a function of size. Each category corresponds to a Berner Impactor stage.

was found that ammonium, nitrate and chloride accounted for $22 \%, 7 \%$ and $15 \%$ respectively of the total mass in the small fraction while the measurements showed $13 \%, 40 \%, 9 \%$ for the same species. For the large fraction the model gave $0 \%, 5 \%, 33 \%$ and the measurements $7 \%$, $5 \%, 28 \%$ again for the same species as above. These can be compared with inputs of $34 \%, 0.3 \%$, $0.7 \%$ and $3 \%, 4 \%, 32 \%$ for the small and large fraction respectively.

In the polluted case, although the total mass added to the aerosol phase was larger than in the clean case, both the model and measurements showed relatively little mass was added to each particle due to the very high number of particles over which the added mass was distributed. Thus, changes in aerosol chemical composition were small.

\subsection{Significance of dynamics details}

A comparison of results from model run $5 \mathrm{~A}$ using the different types of rotor dynamics showed that the presence of the rotor system above the

Tellus 52B (2000), 2 
downwind site made very little difference to the amount of cloud processing despite doubling the length of time particles spent in cloud. Even the multi-cycling case where the parcel goes through the cloud for a second time showed only slight differences in the amount of aerosol modification from the simple case with no rotor present. With a simple doubling of the length of time spent in cloud, the smallest particles activated grew by an additional $3 \%$. With an additional cycle through cloud exactly the same number of particles were activated, despite the smaller updraft used, the smallest particles grew by an additional $6 \%$. These differences can be accounted for by an increased take up of sulphur dioxide and its oxidation to sulphate. Results of this multi-cycling test case are in general agreement with the lagrangian modelling study reported by Dore et al., 1999.

Use of modelled dynamics for the runs where it was available caused slightly smaller particles to activate as the updraft at cloud base was larger than in the prescribed dynamics. With modelled dynamics particles down to $70 \mathrm{~nm}$ activated compared with $85 \mathrm{~nm}$ with prescribed dynamics, this was one additional category in the model. The use of modelled dynamics made a significant difference to the number of cloud droplets present at the summit, as during the polluted events for which modelled dynamics were available, the extra category of particles activated contained a large number of particles. In addition with the prescribed dynamics not all activated particles were still drops by the time the air reached the summit. In some polluted cases the smallest category activated had evaporated by the time the air reached the summit. This was not observed with the modelled dynamics, or with the prescribed dynamics during clean cases.

\section{Conclusions from modelling studies}

Changes in aerosol chemistry and size in both clean and polluted conditions occur due to the following processes:

- Oxidation of sulphur dioxide by hydrogen peroxide, but this is limited, as there is very little sulphur dioxide in the gas phase most already having gone into the aerosol phase as sulphate before the air parcel arrived at Tenerife. Further take up may be inhibited by the low $\mathrm{pH}$ of some of the droplets and short period of time spent in cloud.

- Condensation of nitric acid and hydrogen chloride on the smaller particles and being fixed by ammonia. There is also evidence of loss of nitrate and chloride from the larger particles, which sometimes contributes significantly to that taken up by the smaller particles.

In general in remote environments the exchange of hydrochloric acid, nitric acid and ammonia between aerosol particles in the vicinity of cloud may be a very important mechanism in regulating the evolution of the aerosol spectrum. It is likely that the changes resulting from the uptake of hydrochloric acid, and nitric acid will be permanent when fixed by ammonia and internally mixed with sulphate, but not in other cases. Thus an understanding of the sources and sinks of ammonia in the remote marine environment will be important for interpreting the significance of these results on a more general scale.

The model is able to reproduce the mode in the FSSP measured droplet size distribution during clean studies, but not during polluted studies where the number of droplets is much higher. This is attributed to the FSSP oversizing the droplets due to the high number of coincidence errors in these cases.

The model is able to reproduce the very high numbers of droplets measured during polluted runs, with a linear relationship being established between accumulation mode aerosol and droplet number. Thus supporting the measurements reported in Martinsson et al. (2000). This is very significant in terms of the implications for climate forcing, as clouds consisting of larger numbers of small droplets have a higher albedo than clouds with a similar liquid water content consisting of larger droplets. Thus; the magnitude of the indirect aerosol effect on climate forcing will be larger than previously thought, especially in outbreaks of highly polluted continental air over the ocean. These results will be applied to other clouds in ACE-2 by using the same model to predict the observed numbers of droplets in stratocumulus cloud.

\section{Acknowledgements}

This research is a contribution to the International Global Atmospheric Chemistry 
(IGAC) Core Project of the International Geosphere-Biosphere Programme (IGBP) and is part of the IGAC Aerosol Characterization Experiments (ACE) series. It has been supported by the European Commission under contract number ENV4 CT95 0058 (-PL950583) entitled: "Use of a Hill Cap Cloud to Study Cloud-Aerosol Interactions in ACE-2" (short title: "HILLCLOUD") under the Programme Environment and Climate 1994-1998-Topic 1212. The dynamical calculations have be done on the CRAY C94 and C98 of the "Institut du Developpement et des Ressources en Informatique Scientifique", (IDRIS, CNRS) in Orsay (France) under project no.
940180. The authors would finally like to thank colleagues at collaborating institutes for stimulating discussion, advice and for access to their preliminary and analysed data. These institutes include: Institute of Applied Environmental Research, University of Stockholm; Inst. per lo Studio dei Fenomeni Fisici e Chimici della Bassa ed Alta Atm (FISBAT); Institute of Terrestrial Ecology, Edinburgh Research Station; Division Nuclear Physics, Lund University; Institute of Experimental Physics, University of Vienna; University of East Anglia, UK; Institute of Public and Environmental Health, University of Birmingham.

\section{REFERENCES}

Atkinson, R., Baulch, D. L., Cox, R. A., Hampson, R. F. Jr., Kerr, J. A. and Troe, J. 1989. Evaluated kinetic and photochemical data for atmospheric chemistry supplement. J. of Phys. Chem. Ref. Data 18, 881-1097.

Atkinson, R., Baulch, D. L., Cox, R. A., Hampson, R. F. Jr., Kerr, J. A. and Troe, J. 1992. Evaluated kinetic and photochemical data for atmospheric chemistry supplement IV (IUPAC Subcommittee on Gas Kinetic Data Evaluation for Atmospheric Chemistry). J. of Phys. Chem. Ref. Data 21, 1125-1568.

Betterton, E. A. and Hoffmann, M. R. 1988. Oxidation of aqueous $\mathrm{SO}_{2}$ by peroxymonosulfate. J. Phys. Chem. 92, 5962-5965.

Bower, K. N., Choularton, T. W., Gallagher, M. W., Colville, R. N., Wells, M., Beswick, K. M., Wiedensohler, A., Hansson, H.-C., Svenningson, B., Swietlicki, E., Wendisch, M., Berner, A., Kruisz, C., Laj, P., Facchini, M. C., Fuzzi, S., Bizjak, M., Dollard, G., Jones, B., Acker, K., Wieprecht, W., Preiss, M., Sutton, M. A., Hargreaves, K. J., Storeton-West, R. L., Cape, J. N. and Arends, B. G. 1997. Observation and modelling of the processing of aerosol by a hill cap cloud. Atmos. Environ. 31, 2527-2543.

Bower, K. N., Choularton, T. W., Gallagher, M. W., Colville, R. N., Beswick, K. M., Inglis, D. W. F., Bradbury, C., Martinsson, B. G., Frank, G., Swietlicki, E., Zhou, J., Berg, O. H., Cederfelt, S.-I., Cape, J. N., Sutton, M. A., McFadyen, G. G., Milford, C., Birmili, W., Yuskiewicz, B. A., Wiedensohler, A., Stratmann, F., Wendisch, M., Berner, A., Ctyroky, P., Galambos, Z., Mesfin, S. H., Dusek, U., Dore, C. J., Lee, D. S., Pepler, S. A., Bizjak, M. and Divjak, B. 1999. The Great Dun Fell experiment 1995: an overview. Atmos. Res. 50, 151-184.

Bower, K. N., Choularton, T. W., Gallagher, M. W., Beswick, K. M., Flynn, M. J., Allen, A. G., Davison, B. M., James, J. D., Robertson, L., Harrison, R. M., Hewitt, C. N., Cape, J. N., McFadyen, G. G., Martinsson, B. G., Frank, G., Swietlicki, E., Zhou, J., Berg,
O. H., Mentes, B., Papaspiropoulos, G., Hansson, H.-C., Kulmala, M., Aalto, P., Väkevä, M., Berner, A., Bizjak, M., Fuzzi, S., Laj, P., Facchini, M.-C., Orsi, G., Ricci, L., Nielsen, M., Allan, B. J., Coe, H., McFiggans, G., Plane, J. M. C., Collett Jr., J. L., Moore, K. F. and Sherman. D. E. 2000. ACE-2 HILLCLOUD: An Overview of the ACE-2 ground based cloud experiment. Tellus 52B, 750-778.

Bradbury, C., Bower, K. N., Choularton, T. W., Swietlicki, E., Birmili, W., Wiedensohler, A., Yuskiewicz, B., Berner, A., Dusek, U., Dore, A. J. and McFadyen, G. C. 1999. Modelling of aerosol modification resulting from passage through a hill cap cloud. Atmos. Res. 50, 185-204.

Brandt, C. and van Eldik, R. 1993. Iron(III)-catalyzed oxidation of sulfur(IV)-oxides: evidence for a novel reaction step in the presence of oxygen. Borrell, P. M., Borrell, P., Cvitas, T. and Seiler, W. (eds.): Proceedings of EUROTRAC Symposium '92. SPV Academic Publishing bv, pp. 593-597.

Buxton, G. V., Eccles, J. L. and Salmon, G. A. 1993. The $\mathrm{NO}_{3}$ radical in aqueous solution. Borrell, P. M., Borrell, P., Cvitas, T. and Seiler, W. (eds.): Proceedings of EUROTRAC symposium '92. SPV Academic Publishing bv, pp. 610-614.

Clark, T. L., Hall, W. D. and Banta, R. M. 1994. Twoand three dimensional simulations of the 9 Jan 1989 severe Boulder windstorm: comparison with observation. J. Atmos. Sci. 51, 2317-2342.

Damschen, D. E. and Martin, L. R. 1983. Aqueous aerosol oxidation of nitrous acid by $\mathrm{O}_{2}, \mathrm{O}_{3}$ and $\mathrm{H}_{2} \mathrm{O}_{2}$. Atmos. Environ. 17, 2005-2011.

Deister, U. and Warneck, P. 1990. Photooxidation of $\mathrm{SO}_{3}^{2-}$ in aqueous solution. J. Phys. Chem. 94, 2191-2198.

DeMore, W. B., Sander, S. B., Golden, D. M., Molina, M. J., Hampson, R. F., Kurylo, M. J., Howard, C. J. and Ravishankara, A. R. 1990. Chemical kinetics and

Tellus 52B (2000), 2 
photochemical data for use in stratospheric modelling. In: Jet Propulsion Laboratory Publication 90-1.

Dore, A. J., Johnson, D. W., Osborne, S. R., Choularton, T. W., Bower, K. N., Andreae, M. O. and Bandy, B. J. 2000. Evolution of boundary layer aerosol particles due to in-cloud chemical reactions during the second lagrangian experiment of ACE-2. Tellus 52B, $452-463$.

Dye, J. E. and Baumgardner D. 1984. Evaluation of the forward scattering spectrometer probe. Part 1. Electronic and optical studies. J. of Atmos. and Oceanic Tech. 1, 329-344.

Exner, M., Herrmann, H. and Zellner, R. 1992. Laserbased studies of reactions of the nitrate radical in aqueous solution. Ber. Bunsenges. Phys. Chem. 96, 470-477.

Grenfell, J. L., Savage, N. H., Harrison, R. M., Penkett, S. A., Forberich, O., Comes, F. J., Clemitshaw, K. C., Burgess, R. A., Cardenas, L. M., Davison, B. and McFadyen, G. G. 1999. Tropospheric box-modelling and analytical studies of the hydroxyl $(\mathrm{OH})$ radical and related species: comparison with observations. J. of Atmos. Chem. 33, 183-214.

Huie, R. E. and Neta, P. 1984. Chemical behavior of $\mathrm{SO}_{3}^{-}$and $\mathrm{SO}_{5}^{-}$radicals in aqueous solutions. J. Phys. Chem. 88, 5665-5669.

Jayson, G. G., Parsons, B. J. and Swallow, A. J. 1973. Some simple, highly reactive, inorganic chlorine derivatives in aqueous solution. J. Chem. Soc. Faraday Trans. 69, 1597-1607.

Jokinen, V. and Mäkelä, J. M. 1997. Closed loop arrangement with critical orifice for DMA sheath/excess flow system. J. Aerosol Science 28, 643-648.

Lee, Y. J. and Rochelle, G. T. 1987. Oxidative degradation of organic acid conjugated with sulfite oxidation in flue gas desulfurization: products, kinetics, and mechanism. Env. Sci. Tech. 21, 266-272.

Maahs, H. G. 1983. Kinetics and mechanism of the oxidation of $\mathrm{S}$ (IV) by ozone in aqueous solution with particular reference to $\mathrm{SO}_{2}$ conversion in non-urban tropospheric clouds. J. Geophys. Res. 88C, 10721-10733.

Mäkelä, J. M., Aalto, P., Jokinen, V., Pohja, T., Nissinen, A., Palmroth, S., Markkanen, T., Seitsonen, K., Lihavainen, H. and Kulmala, M. 1997. Observations of ultrafine aerosol particle formation and growth in boreal forest. Geophysical Research Letters 24, 1219-1222.

Martin, L. R. and Damschen, D. E. 1981. Aqueous oxidation of sulfur dioxide by hydrogen peroxide at low pH. Atmos. Environ. 15, 1615-1621.

Martinsson, B. G., Frank, G., Cederfelt, S.-I., Berg, O. H., Mentes, B., Papaspiropoulos, G., Swietlicki, E., Zhou, J., Flynn, M., Bower, K. N., Choularton, T. W., Mäkelä, J., Virkkula, A. and Van Dingenen. R. 2000. Validation of very high cloud droplet number con- centrations in air masses transported thousands of kilometers over the ocean. Tellus 52B, 801-814.

McElroy, W. J. 1990. A laser study of the reaction of $\mathrm{SO}_{4}^{-}$with $\mathrm{Cl}^{-}$and the subsequent decay of $\mathrm{Cl}_{2}^{-}$in aqueous solution. J. Phys. Chem. 94, 2435-2441.

Pandis, S. N. and Seinfeld, J. H. 1989. Sensitivity analysis of a chemical mechanism for aqueous phase atmospheric chemistry. J. Geophys. Res. 94D, 1102-1126.

Pruppacher H. R. and Klett, J. D. 1997. Microphysics of clouds and precipitation, 2nd edition. Kluwer Academic Publications, Dordrecht, pp. 173-174.

Putaud, J. P., Van Dingenen, R., Mangoni, M., Virkkula, A., Raes, F., Maring, H., Prospero, J. M., Swietlicki, E., Berg, O. H., Hillamo, R. and Mäkelä, T. 2000. Chemical mass closure and origin assessment of the submicron aerosol in the marine boundary layer and the free troposphere at Tenerife during ACE-2. Tellus 52B, 141-168.

Reddy, K. B. and Van Eldik, R. 1992. Kinetics and mechanism of the sulfite-induced autoxidation of $\mathrm{Fe}(\mathrm{II})$ in acidic aqueous solution. Atmos. Environ. 26A, 661-665.

Saltelli, A. and Hjorth, J. 1995. Uncertainty and sensitivity analysis of $\mathrm{OH}$-initiated dimethyl sulphide oxidation kinetics. J. of Atmos. Chem. 21, 187-221.

Sander, R., Lelieveld, J. and Crutzen, P. J. 1995. Modelling of the night-time nitrogen and sulfur chemistry in size resolved droplets of an orographic cloud. J. of Atmos. Chem. 20, 89-116.

Schwartz, S. E. 1986. Mass transport considerations pertinent to aqueous phase reactions of gases in liquid clouds. In: Chemistry of multiphase atmospheric systems (ed. W. Jaesckle). Springer Verlag, Berlin, pp. 415-471.

Swietlicki, E., Zhou, J., Berg, O. H., Hameri, K., Vakeva, M., Mäkelä, J., Covert, D. S., Dusek, U., Busch, B., Wiedensohler, A. and Stratmann, F. 2000. Hygroscopic properties of aerosol particles in the eastern Northern Atlantic during ACE-2. Tellus 52B, 201-227.

Virkkula, A., Van Dingenen, R., Raes, F. and Hjorth, J. 1999. Hygroscopic properties of aerosol formed by oxidation of limonene, $\alpha$-pinene, and $\beta$-pinene. $J$. of Geophys. Res. 104, 3569-3579.

Wallace, J. M. and Hobbs, P. V. 1997. Atmospheric science - an introductory survey. Academic Press, ISBN 0127329501, p. 162.

Warneck, P., 1988. Chemistry of the natural atmosphere. Academic Press, Inc., San Diego.

Wine, P. H., Tang, Y., Thorn, R. P., Wells, J. R. and Davis, D. D. 1989. Kinetics of aqueous phase reactions of the $\mathrm{SO}_{4}^{-}$radical with potential importance in cloud chemistry. J. Geophys. Res. 94D, 1085-1094.

Wobrock, W., Flossmann, A. I., Colville, R. N. and Inglis. D. W. F. 1997. Modelling of air flow and cloud fields over the Northern Pennines. Atmos. Environ. 31, 2421-2439.

Yin, F., Grosjean, D. and Seinfeld, J. H. 1990. Photooxidation of dimethyl sulphide and dimethyl disulphide I: mechanism development. J. of Atmos. Chem. 11, 309-364. 